OPEN ACCESS

Edited by:

Reynald Gillet,

University of Rennes 1, France

Reviewed by:

Anil Ojha,

Wadsworth Center, United States

Claude Gutierrez,

Université Toulouse III - Paul Sabatier,

France

${ }^{*}$ Correspondence:

Jarosław Dziadek

jdziadek@cbm.pan.pl

${ }^{\dagger}$ These authors have contributed equally to this work.

Specialty section:

This article was submitted to Microbial Physiology and Metabolism, a section of the journal

Frontiers in Microbiology

Received: 22 June 2017 Accepted: 19 October 2017 Published: 03 November 2017

Citation:

Dadura K, Plocińska $R$ Rumijowska-Galewicz A, Płociński P. Żaczek A, Dziadek B, Zaborowski A and Dziadek J (2017) PdtaS Deficiency Affects Resistance of Mycobacteria to Ribosome Targeting Antibiotics.

Front. Microbiol. 8:2145. doi: 10.3389/fmicb.2017.02145

\section{PdtaS Deficiency Affects Resistance of Mycobacteria to Ribosome Targeting Antibiotics}

\author{
Karolina Dadura ${ }^{1 \dagger}$, Renata Płocińska1t, Anna Rumijowska-Galewicz¹, \\ Przemysław Płociński ${ }^{1}$, Anna Żaczek ${ }^{2}$, Bożena Dziadek ${ }^{3}$, Andrzej Zaborowski ${ }^{1}$ and \\ Jarosław Dziadek ${ }^{1 *}$
}

1 Institute for Medical Biology, Polish Academy of Sciences, Łódź, Poland, ${ }^{2}$ Department of Biochemistry and Cell Biology, University of Rzeszów, Rzeszów, Poland, ${ }^{3}$ Department of Immunoparasitology, University of Łódź, Łódź, Poland

Two-component regulatory systems (TCSSs) are key regulatory elements responsible for the adaptation of bacteria to environmental stresses. A classical TCSS is typically comprised of a sensory histidine kinase and a corresponding response regulator. Here, we used homologous recombination to construct a Mycobacterium smegmatis mutant defective in the synthesis of cytosolic histidine kinase PdtaS (Msmeg_1918). The resulting $\Delta p d t a S$ mutant strain was tested in the Phenotype Microarray screening system, which allowed us to identify aminoglycoside antibiotic sensitivity, tetracyclines antibiotic resistance as well as membrane transport and respiration, as the main processes affected by removal of pdtaS. The antibiotic sensitivity profiles were confirmed by survival assessment and complementation studies. To gain insight into the molecular mechanisms responsible for the observed phenotype, we compared ribosomal RNA and protein profiles of the mutant and wild-type strains. We carried out Northern blotting and qRT-PCR to compare rRNA levels and analyzed ribosome sedimentation patterns of the wild-type and mutant strains on sucrose gradients. Isolated ribosomes were further used to estimate relative abundance of individual proteins in the ribosomal subunits using label free mass spectrometry analysis. Additionally, the $\Delta$ pdtaS mutant revealed lower activity of the respiratory chain as measured by the rate of $\Pi \mathrm{TC}$ (triphenyltetrazolium chloride) reduction, while at the same time showing only insignificant changes in the uptake of aminoglycosides. We postulate that deficiency of PdtaS affects the oxidative respiration rates and ribosomal composition causing relevant changes to intrinsic resistance or susceptibility to antibiotics targeting ribosomes, which are commonly used to treat mycobacterial infections.

Keywords: signal transduction, ribosome, antibiotic resistance, streptomycin, aminoglycosides, tuberculosis

\section{INTRODUCTION}

The genus Mycobacterium possesses pathogens known to cause serious diseases in mammals, including tuberculosis (Mycobacterium tuberculosis) and leprosy (Mycobacterium leprae) in humans as well as saprophytes or non-pathogenic soil bacteria, e.g., Mycobacterium smegmatis. M. smegmatis is a commonly used model species of Mycobacteria that is easy to work with, with a fast doubling time and only requires a biosafety level 1 laboratory. This species shares more than 2000 homologous genes with $M$. tuberculosis and shares the same peculiar cell wall structure of 
M. tuberculosis and other mycobacterial species (King, 2003). It is also capable of oxidizing carbon monoxide aerobically, as is M. tuberculosis.

The evolutionary success of both fast- and slow-growing mycobacteria is based on their ability to adapt to changing growth environments. The bacterium utilizes two-component regulatory systems (TCSSs) to sense and adequately respond to the changing growth conditions. Each system is typically comprised of a sensory histidine kinase that is capable of autophosphorylation when receiving an appropriate stimulus from the environment and subsequently transfers the phosphor group onto its partner protein-the response regulator. The regulatory protein is typically a transcription factor that binds within the promoter regions of a defined set of genes, promoting or repressing their expression. M. tuberculosis possesses 11 pairs of genetically linked TCSSs, as well as five uncoupled orphan regulators and at least two orphan histidine kinases (Bretl et al., 2011). Comparative genomic analyses of the 11 genetically linked TCSSs in M. tuberculosis indicate that homologs of these genes exist also in M. smegmatis (Bretl et al., 2011). Various TCSSs are already implicated in altering the natural antibiotic resistance patterns in mycobacteria (Zhou et al., 2012), while MtrAB and PrrAB systems have been found to be essential for M. tuberculosis survival (Rajagopalan et al., 2010; Haydel et al., 2012). Most response regulators, like MtrA, act as transcriptional regulators; however, in some rare instances, the response regulator can specialize to fulfill other tasks in the cell. This is the case for Escherichia colis CheY, which, upon phosphorylation by its partner sensory kinase, CheA, acts as a flagellar motor switch, binding to the flagella, activating its movement and allowing bacteria to travel to more favorable, nutrient rich niches (Dyer et al., 2009). Another extraordinary group of response regulators includes the ANTAR ( $\underline{A}$ miR and NasR Transcriptional Antitermination Regulator) domain containing proteins. These regulators are believed to form specific antiterminator structures with the newly transcribed RNA, binding stem loop structures or sequences present either in the $5^{\prime}$ UTR regions of regulated transcripts or within the polycistronic RNA species, preventing premature RNA polymerase disengagement (Shu and Zhulin, 2002; Boudes et al., 2012). One of these putative antiterminator proteins, PdtaR (Rv1626), exists in M. tuberculosis and is known to be phosphorylated by its cognate sensory kinase PdtaS (Rv3220c) (Morth et al., 2005). The role of PdtaSmediated phosphorylation remains unclear, as many PdtaR-like antiterminators lack the response regulator domain in other bacterial species and act regardless of their phosphorylation status (Ramesh et al., 2012). Here, the directed KO mutant of M. smegmatis $\Delta p d t a S$ (msmeg_1918) was engineered to investigate the role of PdtaS/R TCSS in resistance to antimicrobial compounds. The Phenotypic Microarray system (BIOLOG) was used to evaluate the sensitivity of the $\Delta p d t a S$ mutant to 240 different chemical agents including antibiotics, detergents and toxic ions. A strong phenotype was identified for aminoglycoside antibiotics, as well as membrane transport and respiration inhibitors. The molecular mechanism of PdtaS-dependent sensitization of mycobacteria to aminoglycosides is discussed in this paper.

\section{MATERIALS AND METHODS}

\section{Bacterial Strains and Growth Conditions}

The M. smegmatis mc $^{2} 155$ (Snapper et al., 1990) strains used in this study were cultured in Middlebrook 7H10 agar or 7H9 broth supplemented with $10 \%$ OADC enrichment (oleic acid albumin dextrose catalase), $0.05 \%$ Tween 80 ( $\mathrm{pH}$ 6.0-6.2), and antibiotics: $50 \mu \mathrm{g} / \mathrm{ml}$ hygromycin (Hyg), or $25 \mu \mathrm{g} / \mathrm{ml}$ kanamycin (Kan).

\section{Gene Cloning Strategies}

Standard molecular biology protocols were used for all cloning procedures (Sambrook and Russell, 2001). All PCR products were obtained using thermostable AccuPrimePfx DNA polymerase (Invitrogen), cloned initially into a blunt vector (pJET 1.2/blunt; Thermo Fisher Scientific), sequenced and then released by digestion with appropriate restriction enzymes before cloning into the final vectors. To facilitate subcloning into expression vectors, restriction enzyme recognition sites were incorporated into the sequence of the primers. The plasmids used in this work are listed in Supplementary Table S1.

\section{Construction of Gene Replacement Vectors and Complementation Plasmids}

A suicidal recombination delivery vector based on p2NIL was used to generate unmarked deletions of pdtaS gene in M. smegmatis (Parish and Stoker, 2000). The recombination vectors carried the $5^{\prime} p d t a S$ upstream region of $1136 \mathrm{bp}$ and the first $79 \mathrm{bp}$ of the pdtaS gene tagged to the $3^{\prime}$ part of the pdtaS gene (807 bp), followed by 448 bp of the pdtaS downstream regions-pKD4. PCR products carrying $5^{\prime}$ and $3^{\prime}$ fragments of the gene were ligated out of frame, such that the resulting $\Delta p d t a S$ gene encoded a short, non-functional protein. Finally, the PacI screening cassette from pGOAL17 was inserted into the constructs, resulting in the suicide delivery vector pKD5 which was used to engineer the directed $M$. smegmatis mutant as described previously (Dziadek et al., 2002; Brzostek et al., 2009; Plocinska et al., 2012). The required plasmids and primers are listed in Supplementary Table S1.

To prepare the complementation plasmid, intact $p d t a S$ gene from M. smegmatis was PCR amplified (using primers listed in Supplementary Table S1) and cloned into BamHI-HindIII sites of pKW08Lx vector downstream of the $P_{\text {tet }}$ promoter (Supplementary Table S1). Next, the gene and the $P_{\text {tet }}$ promoter were excised from the resulting vector (pKL5) with HindIII and XbaI and cloned into the integrating vector pKW08Lx-Int, generating $\mathrm{pKD} 10$.

\section{Disruption of $M$. smegmatis pdtaS}

The protocol of Parish and Stoker (2000) was used to disrupt the M. smegmatis pdtaS gene at its native loci on the chromosome. The suicidal recombination plasmid DNA (pKD5) was treated with $\mathrm{NaOH}(0.2 \mathrm{mM})$ and integrated into the $M$. smegmatis chromosome by homologous recombination. The resulting single crossover recombinant (SCO) mutant colonies were blue, $\operatorname{Kan}^{\mathrm{R}}$ and sensitive to sucrose. The site of recombination was confirmed by PCR and Southern hybridization (data not shown). The SCO 
strains were further processed to select for double crossover (DCO) mutants that were white, $\mathrm{Kan}^{\mathrm{S}}$ and resistant to sucrose (2\%). The genotypes of obtained mutant DCO strains were confirmed by PCR and Southern hybridization. Probes to hybridize to the $p d t a S$ gene were generated by PCR by labeling with a non-radioactive primer extension system (DIG-labeling system, Amersham). Primers used for PCR amplification are listed in Supplementary Table S1.

\section{Phenotypic Microarrays}

The M. smegmatis wild-type strain and $\Delta p d t a S$ mutant were initially grown on $7 \mathrm{H} 10 / \mathrm{OADC}$ at $37^{\circ} \mathrm{C}$. Colonies were suspended in inoculation fluid (IF0a - BIOLOG protocol) using a sterile swab to a final transmittance of $81 \%$. The redox indicator tetrazolium violet was added to every cell suspension according to the PM BIOLOG protocol appropriate for PM plates. Next, every well of the PM11-PM20 plates was inoculated by adding $100 \mu \mathrm{l}$ of the suspension of bacterial cells. The PM11-PM20 plates contained 240 different chemicals, each at four different concentrations. Inoculated PM plates were incubated at $37^{\circ} \mathrm{C}$ in a BIOLOG Omnilog incubator, which allowed for collection of a set of growth kinetic related measurements every $15 \mathrm{~min}$ during the $72 \mathrm{~h}$ of incubation time. The bacterial growth was estimated as a rate of reduction of the tetrazolium violet to a purple colored formazan proportionally to the respiration of bacteria. The intensity of the purple color was recorded as a value and plotted by the software in an automated manner. Then, the growth of the wild-type and mutant strains in the presence of a given chemical was compared by overlapping the area under the curve (AUC) for respective conditions. AUC values from each well for wild-type and mutant strains collected in at least two independent experiments were exported from the BIOLOG software into an Excel file format and analyzed. The difference in AUC between the wild-type and mutant strains was due to different growth dynamics or different survival rates in the presence of tested antibiotics, detergents and toxic ions.

\section{Spot Dilution Assay}

Exponentially grown $M$. smegmatis cells were initially diluted to an optical density $\mathrm{OD}_{600}$ of 0.5 - and 10-fold serial dilutions were prepared. $10 \mu \mathrm{l}$ of cells from each dilution $\left(10^{0}, 10^{-1}, 10^{-2}, 10^{-3}\right.$, $10^{-4}$ ) were spotted onto $7 \mathrm{H} 10$ solid medium containing OADC and different ranges of concentration of antibiotics: apramycin $(0.1-0.7 \mu \mathrm{g} / \mathrm{ml})$, sisomicin $(0.5-2.0 \mu \mathrm{g} / \mathrm{ml})$, streptomycin (SM-0.3 - $2.0 \mu \mathrm{g} / \mathrm{ml}$ ), dihydrostreptomycin (DIH-SM - $0.2-$ $1.0 \mu \mathrm{g} / \mathrm{ml})$, kanamycin $(1.0-2.5 \mu \mathrm{g} / \mathrm{ml})$, tetracycline (TET- $0.1-$ $1.0 \mu \mathrm{g} / \mathrm{ml})$. Plates were incubated at $37^{\circ} \mathrm{C}$ for $3-5$ days and photographed. Three independent repetitions were performed.

\section{Survival Assessment in the Presence of Growth Inhibitors}

The survival of $M$. smegmatis $\Delta p d t a S$ mutant cells grown in liquid medium with the addition of chosen antibiotics was studied using standard CFU methodology. Actively growing cells from the logarithmic stage of growth were diluted in
7H9 medium supplemented with OADC and Tween-80 to an $\mathrm{OD}_{600}$ of 0.1 . Chosen antibiotics were used at the following final concentrations: apramycin $0.55 \mu \mathrm{g} / \mathrm{ml}$, sisomicin $2.3 \mu \mathrm{g} / \mathrm{ml}$, streptomycin $0.5 \mu \mathrm{g} / \mathrm{ml}$, dihydrostreptomycin $0.5 \mu \mathrm{g} / \mathrm{ml}$, kanamycin $2.0 \mu \mathrm{g} / \mathrm{ml}$ and tetracycline $0.1 \mu \mathrm{g} / \mathrm{ml}$, which was based on the results of the spot dilution assay. The kinetics of growth was measured by recording $\mathrm{OD}_{600}$ at 3, 6, 9, and $24 \mathrm{~h}$ after addition of antibiotics. At the 9 and $24 \mathrm{~h}$ time points, 10 -fold serial dilutions of cells were spread on $7 \mathrm{H} 10$ agar containing OADC. Plates were incubated at $37^{\circ} \mathrm{C}$ for 3-5 days, colonies were counted and data were plotted using Excel. A Student's $t$-test was performed to determine the statistical significance between the test and control values. All statistical calculations were performed with help of the SigmaPlot 12.0 software.

\section{Minimum Inhibitory Concentration (MIC) of Aminoglycoside Antibiotics}

In order to determine the MIC values for tested here antibiotics, the microplate Alamar blue assay (MABA test) was employed as described previously (Franzblau et al., 1998), with minor modifications. All microplate Alamar blue assays were performed using 96-well flat-bottom plates (Techno Plastic Products). The standardization of the bacterial cell number used for MABA test is critical for obtaining accurate and reproducible results. Thus, the recommended final inoculum was prepared at $5 \times 10^{5}$ $\mathrm{CFU} / \mathrm{ml}$ by diluting logarithmic phase grown cultures with $7 \mathrm{H} 9$ broth supplemented with 10\% OADC and Tween-80 initially to a $0.5 \mathrm{McFarland}$ turbidity and $100 \mathrm{X}$ further for inoculation (Luna-Herrera et al., 2003; Wiegand et al., 2008).

The microdilution of antibiotics (kanamycin, streptomycin, dihydrostreptomycin, apramycin, sisomicin, tetracycline) was performed in 96-well plates. Two-fold dilutions of each antibiotic were prepared in the test wells in complete $7 \mathrm{H} 9$ broth and the final antibiotic concentration ranges were as follows: kanamycin $6-0.046 \mu \mathrm{g} / \mathrm{ml}$, streptomycin $5-0.04 \mu \mathrm{g} / \mathrm{ml}$, dihydrostreptomycin $5-0.04 \mu \mathrm{g} / \mathrm{ml}$, apramycin $5-0.04 \mu \mathrm{g} / \mathrm{ml}$ and sisomicin $4-0.03 \mu \mathrm{g} / \mathrm{ml}$, tetracycline $4-0.03 \mu \mathrm{g} / \mathrm{ml}$. One hundred microliters of each bacterial suspension was added to $100 \mu \mathrm{l}$ of drug-containing culture medium. The plates were incubated for $48 \mathrm{~h}$ at $37^{\circ} \mathrm{C}$ and this time point $25 \mu \mathrm{l}$ of Alamar blue solution (Invitrogen) was added to each well. Plates were incubated at $37^{\circ} \mathrm{C}$ for additional $24 \mathrm{~h}$ (Chung et al., 1995; Banfi et al., 2003). After incubation time plates were read for color change from blue to pink and absorbance was measured at 570/600 nm (Benchmark Plus Microplate Spectrophotometer, Bio Rad). Wells containing only bacteria, medium, or antibiotic were used as controls in each plate. MIC was defined as the lowest concentration of antibiotic that prevented color change from blue to pink. The MIC value for each antibiotic was determined from at least three independent experiments.

\section{The Uptake of Streptomycin}

The bacterial cells were cultured in 7H9 medium supplemented with OADC and Tween-80 up to $\mathrm{OD}_{600}$ 0.5. Based on the results from the spot dilution assay, $20 \mathrm{ml}$ of mycobacterial cells were exposed to streptomycin at a final concentration of 
$0.7 \mu \mathrm{g} / \mathrm{ml}$ for 60 and $180 \mathrm{~min}$. After pre-incubation with the tested antibiotic, the bacilli were centrifuged, washed with $7 \mathrm{H} 9$ medium and bead-beated twice for $45 \mathrm{~s}, 6.0 \mathrm{~m} / \mathrm{s}$ using the Ms disruptor system with Quick prep adapter (MP Biomedicals). The streptomycin uptake by the cells of the wild-type and mutant strains of M. smegmatis was monitored with application of the commercially available competitive immunoenzymatic Green Spring Streptomycin ELISA test Kit (Antibodies-online Inc., United States) according to manufacturer's indications. The mathematical calculations of the SM concentrations in the experimental and control tubercle bacilli cell lysates were based on the standard curve that was established following the procedure recommended by the manufacturer.

\section{Microplate Alamar Blue Assay}

The microplate Alamar blue assay was applied to study respiratory activity of $M$. smegmatis by monitoring resazurin reduction. $200 \mu \mathrm{l} /$ well $\left(1 \times 10^{6}\right.$ cells $\left./ \mathrm{ml}\right)$ of $\Delta p d t a S$ and wildtype $M$. smegmatis cells were seeded in triplicate into a 96-well plate. Then, $25 \mu \mathrm{l}$ of Alamar blue reagent was added into each well directly after inoculation and the plate was incubated at $37^{\circ} \mathrm{C}$ in a humidified atmosphere. The optical density of the plate was measured at $570 \mathrm{~nm}$ and $600 \mathrm{~nm}$ at 0,7 , and $11 \mathrm{~h}$ of growth using Benchmark Plus Microplate Spectrophotometer (BioRad). Data were plotted using Excel.

\section{Respiration Activity Assay Using 2,3,5-Triphenyltetrazolium Chloride (TTC)}

TTC powder was dissolved in sterile distilled water at a concentration of $5 \mathrm{mg} / \mathrm{ml}$ at room temperature, then filtered through $0.22 \mu \mathrm{m}$ syringe filters. $\Delta p d t a S$ and wildtype $M$. smegmatis cells from the logarithmic phase of growth were diluted to $1 \times 10^{6}$ cells $/ \mathrm{ml}$ and seeded into a 96-well plate. Next, TTC at a final concentration of $0.625 \mathrm{mg} / \mathrm{ml}$ was added to $200 \mu \mathrm{l}$ of diluted culture. The plate was incubated at $37^{\circ} \mathrm{C}$ and red formazan formation was measured at $480 \mathrm{~nm}$ at 0,2 , and $7 \mathrm{~h}$ timepoints of incubation by Benchmark Plus Microplate Spectrophotometer (BioRad). To determine any significant differences between studied strains the Student's $t$-test was applied. The statistically significant difference was calculated as $(P \leq 0.001)$.

\section{RNA Isolation and Northern Blotting Analysis}

Total RNA was extracted from the wild-type $M$. smegmatis strain and corresponding $\Delta p d t a S$ mutant strain as described previously (Pawelczyk et al., 2011). Briefly, $15 \mathrm{ml}$ of cells from logarithmic and stationary phases of growth were centrifuged at $4500 \mathrm{rpm}$ for $10 \mathrm{~min}$ at $4^{\circ} \mathrm{C}$. The cell pellet was resuspended in $300 \mu \mathrm{l}$ of DEPC water and $900 \mu \mathrm{l}$ of Trizol LS reagent (Invitrogen) was added and transferred into screw cap tubes containing $500 \mu \mathrm{l}$ of $0.1 \mathrm{~mm}$ silica spheres (MP Biomedicals). Cells were disrupted twice for $45 \mathrm{~s}, 6.0 \mathrm{~m} / \mathrm{s}$ with $5 \mathrm{~min}$ intervals on ice using an MP disruptor system with Quick prep adapter (MP Biomedicals). Then, DNase I (Invitrogen) was used to remove DNA contamination according to the manufacturer's instructions.
The levels of precursor ribosomal RNA species and their processing intermediates were monitored by Northern blotting analysis. Samples of $2 \mu \mathrm{g}$ of total RNA from two independent biological replicates were resolved in a denaturing $1.2 \%$ agarose gel containing formaldehyde in 1X NBC buffer $\mathrm{pH} 7.5(50 \mathrm{mM}$ boric acid, $1 \mathrm{mM}$ sodium acetate, $5 \mathrm{mM} \mathrm{NaOH}$ ) and $0.9 \%$ formaldehyde (Szczesny et al., 2010). Gel was transferred onto a Hybond+ nylon membrane by capillary transfer in 20xSSC pH 7.0 (3 M NaCl, 0.3 M sodium citrate) buffer overnight. Next, RNA was immobilized by cross-linking to the membrane with UV260, stained with methylene blue to confirm transfer efficiency and used for hybridization with $\gamma$ - ${ }^{32}$ P-ATP labeled, 20-25 bp long oligonucleotide probes complementary to the transcript tested (for primer sequences see Supplementary Table S1). After extensive washing, the membrane was incubated in a phosphorimaging screen and cassette and the screen was scanned in the Typhoon apparatus to visualize the results.

\section{Quantitative Real Time (qRT) PCR}

The same RNA samples tested for Northern blotting were used for quantitative real time PCR (qRT-PCR) analysis of transcript levels for $16 \mathrm{~S}, 23 \mathrm{~S}$ and $5 \mathrm{~S}$ genes. The reverse transcription reaction and qRT-PCR analysis were performed as described previously by Pawelczyk et al. (2011). Briefly, $1 \mu \mathrm{g}$ of total RNA was reverse transcribed using specific primers to each studied gene (Supplementary Table S1) and the SuperScript III FirstStrand Synthesis SuperMix (Invitrogen). qRT-PCR analysis of expression levels of $16 \mathrm{~S}, 23 \mathrm{~S}$ and $5 \mathrm{~S}$ genes was performed using the Maxima SYBR green qPCR master mix (Thermo Fisher Scientific). Each reaction mixture at a final volume of $25 \mu \mathrm{l}$ contained $1 \mathrm{x}$ Maxima SYBR green qPCR master mix, $50 \mathrm{ng}$ of cDNA, and $0.3 \mathrm{M}$ of each primer (see Supplementary Table S1 for primer sequences). The qRT-PCR reaction was carried out in a $7900 \mathrm{HT}$ real time PCR system (Applied Biosystems). The three step cycling protocol was used for transcript analysis of $16 \mathrm{~S}, 23 \mathrm{~S}$ and $5 \mathrm{~S}$ : initial denaturation at $95^{\circ} \mathrm{C}$ for $10 \mathrm{~min}$, followed by 40 cycles at $95^{\circ} \mathrm{C}$ for $15 \mathrm{~s}$ (denaturation), $56^{\circ} \mathrm{C}$ for $30 \mathrm{~s}$ (annealing), $72^{\circ} \mathrm{C}$ for $30 \mathrm{~s}$ (extension). Data were collected and acquired during the extension step. The melting curve analysis was performed at the end of each PCR in order to verify the specificity of the generated PCR product. All the reactions were performed in triplicate and three different RNA samples from independent experiments were tested. The results were normalized to $16 \mathrm{~S}, 23 \mathrm{~S}$ and $5 \mathrm{~S}$ copy number of the DNA standard curve as described (Gagala et al., 2014). To prepare the calibration standards, the $M$. smegmatis $16 \mathrm{~S}$ and 23S-5S transcript sequences were cloned into pJET1.2/blunt vector (Thermo Fisher Scientific). The obtained plasmids pKD11 and pKD12 were linearized by restriction digestion with NcoI and ScaI, respectively, and the gene copy number per $\mu l$ was determined. Then, serial 10 -fold dilutions of $2 \times 10^{10}$ copies of each gene were used to make the standard curve.

\section{Ribosome Analysis}

Appropriate mycobacterial strains were grown exponentially in $250 \mathrm{ml}$ of $7 \mathrm{H} 9$ media and were pelleted and frozen over a liquid nitrogen bath. When needed, cells where thawed and lysed in 
lysis buffer containing $20 \mathrm{mM}$ HEPES pH 7.5, $200 \mathrm{mM} \mathrm{KCl}$, $5 \mathrm{mM} \mathrm{MgCl}_{2}, 1 \%$ Triton X-100, $2 \mathrm{mM} \mathrm{DTT,} 5 \mathrm{U} / \mathrm{ml}$ of DNase turbo (Thermo Fisher Scientific) using the same procedure as described for total RNA isolation. Cell lysate was precleared by centrifugation at $14,000 \mathrm{rpm}$ for $20 \mathrm{~min}$, passed through a $0.22 \mu \mathrm{m}$ Ultra free-MC microcentrifuge filter (Millipore) and overlaid onto a freshly prepared continuous $7-47 \%$ sucrose gradient (Esposito et al., 2010). The samples were spun at $39,000 \mathrm{rpm}$ for $2 \mathrm{~h}$ with "no brake" deceleration in a swinging bucket TH641 rotor using Thermo Sorvall WX90 ultracentrifuge and gradients were collected using an AKTA Purifier (GE Healthcare) equipped with UV monitor. Ribosomal spectra were recorded and plotted for comparison.

For comparative proteomic analysis, fractions containing ribosomal subunits separated by their sedimentation indexes were split in half and precipitated using PRM reagent (acidified pyrogallol red). Protein precipitates were either run on an SDS-PAGE gel or directly analyzed using mass spectrometry (MS/MS). The protein gels were inspected visually and the single band that differed the most between the wild-type and mutant isolations was excised and subjected to MS/MS identification. The MS analysis was performed similarly as described elsewhere (Plocinski et al., 2014). Briefly, protein samples were reduced with DTT, alkylated using iodoacetamide and subjected to standard Trypsin digestion. Resulting peptide mixtures were loaded onto RP-18 pre-columns and transferred to a nano-HPLC RP-18 column in acetonitrile gradient. The HPLC system's outlet was directly connected to the Orbitrap Velos (Thermo Fisher Scientific). The data-dependent mode of data collection was used, which allowed us to switch between Orbitrap MS and LTQ-MS/MS acquisition. Obtained "-.raw" files were next processed by MaxQuant software (v1.3.0.5) using default search parameters against the randomized M. smegmatis database and results were exported to Excel format.

\section{$\beta$-Galactosidase Activity Assay}

Mycobacterium smegmatis $\Delta p d t a S$ and wild-type cells carrying an integration plasmid expressing lac $Z$ gene under the acetamide promoter were grown in broth (7H9, Tween-80, OADC) with addition of SM - 0.7, 0.2, and $0.1 \mu \mathrm{g} / \mathrm{ml}$, DIH-SM - 0.5, 0.05, and $0.01 \mu \mathrm{g} / \mathrm{ml}$ and TET $-0.1 \mu \mathrm{g} / \mathrm{ml}$ from $\mathrm{OD}_{600} 0.15$ for $6 \mathrm{~h}$ to mid-logarithmic phase of growth. The cells from each culture (1 ml) were disrupted using an MP disruptor system with Quick prep adapter (MP Biomedicals), $2 \times 45 \mathrm{~s}, 6.0 \mathrm{~m} / \mathrm{s}$ with $5 \mathrm{~min}$ intervals on ice. Cells were harvested (5 min, $14000 \mathrm{rpm}$ at room temperature) and supernatants were used to determine the $\beta$-galactosidase activity according to the protocol by Karimova et al., 2000. Briefly supernatants were mixed with PM2 buffer (70 mM Na $2 \mathrm{HPO}_{4} \mathrm{X}_{12} \mathrm{H}_{2} 0,30 \mathrm{mM} \mathrm{NaH} \mathrm{PO}_{4} \mathrm{XH}_{2} 0,1 \mathrm{mM}$ $\mathrm{MgSO}_{4}, 0.2 \mathrm{mM} \mathrm{MnSO} 4,100 \mathrm{mM} \beta$-mercaptoethanol), reaction was started by addition of $0.4 \% \quad o$-nitrophenol- $\beta$-galactoside $(\mathrm{ONPG})$ and incubated at $28^{\circ} \mathrm{C}$ for $20 \mathrm{~min}$. The reaction was terminated by adding sodium carbonate to $0.5 \mathrm{M}$ final concentration. Next, the absorbance at $420 \mathrm{~nm}$ was recorded and the enzymatic activity was calculated in relation to the starting $\mathrm{OD}_{600}$ of each tested culture.

\section{RESULTS}

\section{The pdtaS Gene Product Is Not Essential for Growth and Survival of M. smegmatis Cells}

Compared to the genetically linked two component signal transduction systems from mycobacteria, very little is known about the orphaned elements of the signaling cascade in these bacteria. PdtaS (rv3220c) was previously shown to be a nonessential gene in $M$. tuberculosis and has been disrupted by Parish and collaborators (Parish et al., 2003). To evaluate the role of the PdtaS sensor kinase in mycobacteria, we constructed a M. smegmatis pdtaS deletion strain using two-step homologous recombination (Parish and Stoker, 2000). The list of plasmid constructs and primers used in this study is provided in Supplementary Table S1. The obtained single crossover (SCO) recombinants carrying both the wild-type pdtaS copy and the $\Delta p d t a S$ copy with an internal deletion, verified by PCR (data not shown), were screened following the protocol for double crossover selection (DCOs). Our numerous attempts to construct a knockout mutant strain of $\Delta p d t a S$ in M. smegmatis cells were unsuccessful, thus we first generated the conditional pdtaS mutant in the SCO background with an attB-integrated pKW08 vector carrying the intact $p d t a S$ gene under tetracycline promoter ( $\mathrm{pKD} 10)$. The resulting strain was subjected to a second crossover event screening to generate double crossovers and the pKD10 plasmid was later swapped efficiently with an empty pMV306 plasmid, which was finally lost by culturing bacteria without antibiotic pressure. The genotype of $\Delta p d t a S$ M. smegmatis mutant strain was confirmed by PCR and Southern blot hybridization (Supplementary Figure S1). Analysis of growth kinetics by measurements of optical density of liquid cultures at $600 \mathrm{~nm}$ and viability (CFU/ml) for $\Delta p d t a S$ M. smegmatis cells revealed only modest differences comparing to the wild-type strain when grown in liquid media (Supplementary Figure S2).

\section{M. smegmatis $\Delta$ pdtaS Mutant Reveals Altered Sensitivity to Aminoglycosides, As Well As to Inhibitors of Membrane Transport and Respiration, When Tested in Phenotype Microarray Profiling}

To investigate the impact of PdtaS deficiency on fitness and properties of mycobacterial cells, we applied the BIOLOG Phenotype Microarray screening platform, which allows for convenient testing of growth kinetics of bacteria challenged against multiple antibiotics, detergents, oxidizing agents and toxic compounds. Overall, we exploited 10 PM plates (PM11-20) containing 240 different chemical agents, each arranged in 4 increasing concentrations in a 96-well plate format for simultaneous testing.

When comparing AUCs (the AUC) values of the wildtype $M$. smegmatis and the $\Delta p d t a S$ mutant, several changes were noted with major alterations in sensitivity profiles to inhibitors of respiration and membrane electron transport, as well as antibiotics targeting the $30 \mathrm{~S}$ subunit of the ribosome 
(Supplementary Table S2). The sensitization phenotype of $\Delta p d t a S$ (AUCs difference $>8500$ ) was observed with the use of aminoglycosides such as tobramycin (>21000), sisomicin, apramycin (>13000), neomycin (>12000), streptomycin $(>10000)$, amikacin $(>9000)$ and gentamicin $(>8500)$. On the other hand, the mutant strain appeared to be more resistant to dihydrostreptomycin $(>-22000)$, another antibiotic targeting the $30 \mathrm{~S}$ subunit of the ribosome. It is worth noting that amikacin, kanamycin and streptomycin are currently being used as antituberculosis agents, and knowing that their activity may be improved by affecting the expression profile of PdtaS might be useful in future treatment strategies.

The sensitization phenotype of $\Delta p d t a S$ was also observed with the use of inhibitors of respiration and membrane electron transport. The most potent effect was observed for the inhibitors of respiration such as pentachlorophenol (AUCs difference $>20000)$, menadione and hexachlorophene ( $>10000)$. The potent sensitization phenotype was also observed in the presence of compounds affecting transmembrane proteins (sanguinarine and guanidine hydrochloride, $>15000$ and 14000, respectively). On the other hand, the $\Delta p d t a S$ strain was more resistant to other inhibitors of membrane transport and respiration, colistin and iodonitro tetrazolium violet (AUCs difference $>-14000)$.

Additionally, the PdtaS mutant appeared to be more resistant to several additional compounds, including antibiotics such as tetracycline, blasticidin $S$, penimepicycline, rifampicin, oxacillin, cloxacillin and vancomycin (Supplementary Table S2).

\section{Inactivation of pdtaS Causes Sensitivity of $M$. smegmatis to 30 S Targeting Antibiotics}

Having identified $30 \mathrm{~S}$ targeting antibiotics as key agents influencing the survival of $M$. smegmatis lacking pdtaS in the Phenotype Microarray, we set out to confirm these observed effects in $M$. smegmatis using spot dilution assays. This relatively simple technique requires spotting 10 -fold dilutions of bacteria onto solid growth medium plate containing known amounts of tested antibiotics. Alongside the wild-type and the deletion mutant strain, we included a complementation strain carrying an intact pdtaS gene under $P_{\text {tet }}$ promoter on an external plasmid, while the genomic locus remains disrupted. This was to prove that observed effects can indeed be attributed to the inactivation of pdtaS as a single causing factor and ectopic expression of PdtaS should reverse the observed phenotypes back to the wild-type patterns. We have chosen to test different ranges of concentrations of apramycin, sisomicin, streptomycin, dihydrostreptomycin and kanamycin, as the mode of action for these antibiotics is well characterized (Supplementary Figure $\mathrm{S} 3 \mathrm{~A}$ ), and they are known to be stable on solid media plates. In fact, kanamycin and streptomycin are used in routine molecular microbiology practice as genetic markers.

The spot dilution assay confirmed the sensitivity patterns previously observed in the Phenotype Microarray for all chosen antibiotics, with the exception of dihydrostreptomycin (Supplementary Figure S3B). Interestingly, in contradiction to the Phenotypic Microarray analyses, M. smegmatis $\Delta p d t a S$ cells showed reduced survival in the presence of dihydrostreptomycin, confirming the sensitization of the $\Delta p d t a S$ mutant to all tested aminoglycosides.

To further confirm the observed results, the viable colonyforming units per milliliter $(\mathrm{CFU} / \mathrm{ml})$ of $\Delta p d t a S$ mutant cells in the presence of antibiotics were determined. CFU data indicate a significant reduction in viability of $\Delta p d t a S$ cells compared to the wild-type and the complementation strain in the presence of all aminoglycoside antibiotics tested in liquid medium. After $24 \mathrm{~h}$ of growth, the survival of $\Delta p d t a S$ cells in the presence of kanamycin $(2.0 \mu \mathrm{g} / \mathrm{ml})$ or streptomycin $(0.5 \mu \mathrm{g} / \mathrm{ml})$ was reduced by approximately $60 \%$ compared to the wild-type strain. Addition of apramycin $(0.55 \mu \mathrm{g} / \mathrm{ml})$ or dihydrostreptomycin $(0.5 \mu \mathrm{g} / \mathrm{ml})$ resulted in growth inhibition of mutant cells by approximately 75 or $80 \%$, respectively, in respect to the control strain. Sisomicin $(2.3 \mu \mathrm{g} / \mathrm{ml})$ affected the survival of $\Delta p d t a S$ by approximately $90 \%$ in comparison to the wild-type strain. Interestingly, the $\Delta p d t a S$ mutant strain was more resistant to the presence of tetracycline $(0.1 \mu \mathrm{g} / \mathrm{ml})$ in the growing medium, in comparison to the wild-type strain. The survival of $M$. smegmatis wild-type cells was inhibited by about $65 \%$ in comparison to $\Delta p d t a S$ cells. Concentrations of antibiotics used for CFU assessment were chosen based on results obtained in the spot dilution assay. The obtained data for all antibiotics used in this study, were considered statistically significant using Student $t$-test (Figure 1). All the observed phenotypes were fully reversible when a complementing copy of pdtaS gene under its native promoter was introduced into the $\Delta p d t a S$ mutant strain. Finally, the minimal inhibitory concentration (MIC) for the all tested antibiotics was determined using microplate Alamar blue assay (MABA). In this assay, the presence of mycobacterial growth causes the redox indicator Alamar blue to turn from blue to pink (Leonard et al., 2008). The obtained MIC values are presented in Table 1. The results confirmed significant sensitization of the PdtaS deficient strain to kanamycin, streptomycin and dihydrostreptomycin. Surprisingly, the MIC values for apramycin and sisomycin remained on the wild-type level, despite the BIOLOG, CFU analysis and spot assay results all indicating growth defect of PdtaS mutant strain, when cultured in the presence of tested antibiotics. Results obtained from MIC for tetracycline confirmed previous observations (BIOLOG, CFU and spot dilution assay) that the $\Delta p d t a S$ strain is more resistant to tetracycline in comparison to the wild-type strain.

The MIC obtained for kanamycin was $1.5 \mu \mathrm{g} / \mathrm{ml}$ for wild-type and complimenting strain and $0.75 \mu \mathrm{g} / \mathrm{ml}$ for the mutant strain. Analysis for other antimicrobial agents showed considerably lower MIC than for kanamycin. MIC for streptomycin was $0.625 \mu \mathrm{g} / \mathrm{ml}$ for Ms-wt and $\Delta p d t a S$ - pdtaS strains and $0.312 \mu \mathrm{g} / \mathrm{ml}$ for $\Delta p d t a S$ strain. MIC for dihydrostreptomycin is $0.312 \mu \mathrm{g} / \mathrm{ml}$ for Ms-wt and $\Delta p d t a S$ - pdtaS strains and $0.156 \mu \mathrm{g} / \mathrm{ml}$ for $\Delta p d t a S$ strain. Values of MIC for apramycin and sisomicin are equal to all tested strains and they are respectively $1.25 \mu \mathrm{g} / \mathrm{ml}$ and $2 \mu \mathrm{g} / \mathrm{ml}$. The obtained MIC for tetracycline was $0.5 \mu \mathrm{g} / \mathrm{ml}$ for the $\Delta p d t a S$ strain and $0.25 \mu \mathrm{g} / \mathrm{ml}$ for the wild-type and complementing strains. 
A

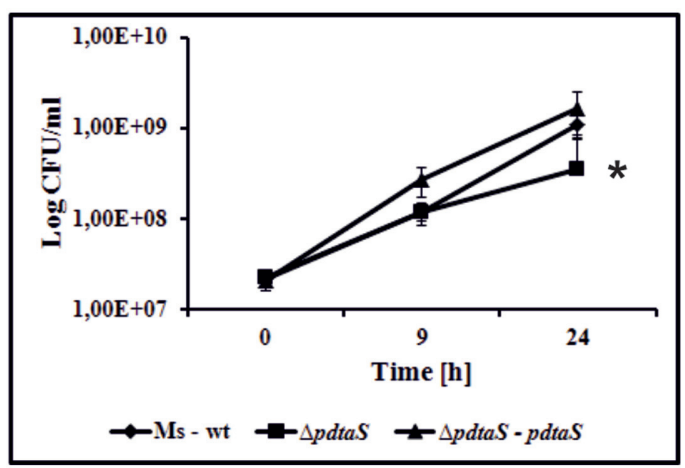

C

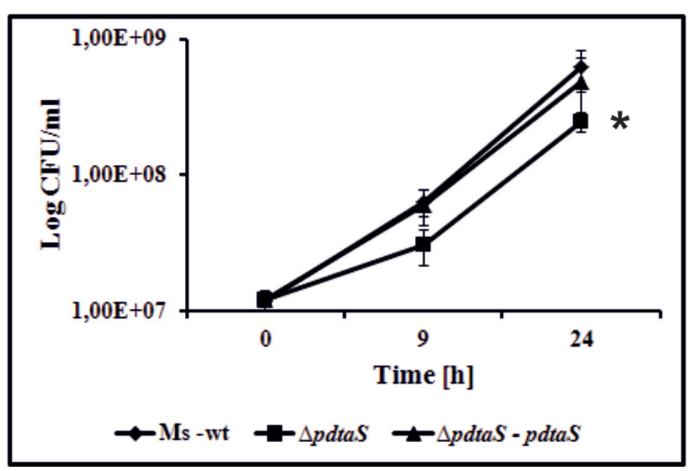

E

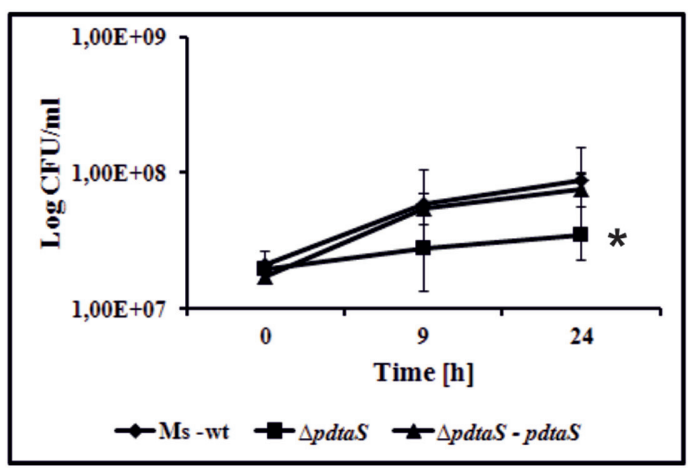

B

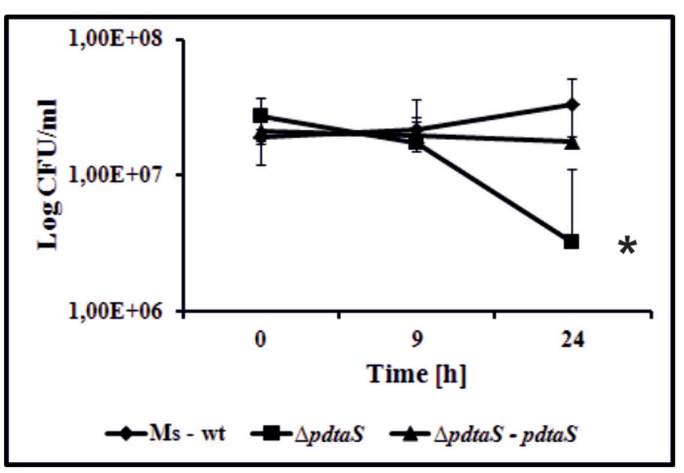

D

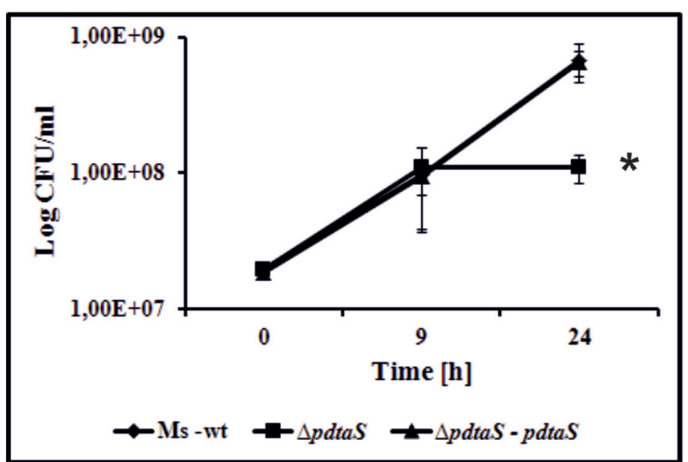

$\mathbf{F}$

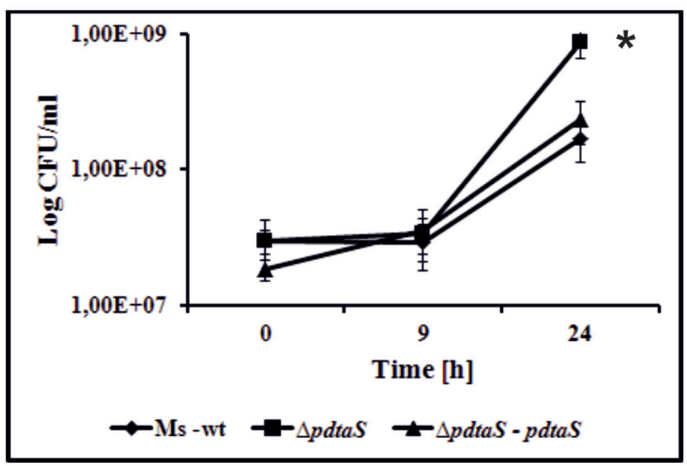

FIGURE 1 | PdtaS deficiency alters sensitivity of $M$. smegmatis cells to various aminoglycoside antibiotics. The $M$. smegmatis wild-type (Ms-wt), mutant $\Delta p d t a S$ and $\Delta$ pdtaS complemented strain ( $\Delta$ pdtaS-pdtaS) were propagated in $7 \mathrm{H} 9$ medium supplemented with OADC. Time-dependent CFU/ml was determined after 9 and $24 \mathrm{~h}$ of cell exposure to aminoglycoside antibiotics: (A) $0.55 \mu \mathrm{g} / \mathrm{ml}$ apramycin, (B) $2.3 \mu \mathrm{g} / \mathrm{ml}$ sisomicin, (C) $0.5 \mu \mathrm{g} / \mathrm{ml}$ streptomycin, (D) $0.5 \mu \mathrm{g} / \mathrm{ml}$ dihydrostreptomycin, (E) $2.0 \mu \mathrm{g} / \mathrm{ml}$ kanamycin, (F) $0.1 \mu \mathrm{g} / \mathrm{ml}$ tetracycline. Colony formation values are means \pm standard errors from three independent experiments. The statistical analyses were performed using the Student's $t$-test (apramycin, $P=0.012$; streptomycin, $P \leq 0.001$; sisomicin, $P=0.007$; dihydrostreptomycin, $P \leq 0.001$; kanamycin, $P \leq 0.001$; tetracycline, $P=0.009$ ).

This clearly indicates that the activity of PdtaS as a single causing factor is indeed responsible for the observed sensitization of the mutant strain to aminoglycoside antibiotics.

\section{Removal of PdtaS Moderately Influences Oxidative Respiration Efficiency}

The data mining indicated that PdtaS may be linked to reaeration and oxygen sensing. On the other hand, from the Phenotype Microarray platform, we have observed alterations in sensitivity of the $\Delta p d t a S$ strain to compounds interfering with the respiratory chain. It was previously shown that electron motive force can influence sensitivity or resistance patterns against aminoglycosides (Taber et al., 1987). To verify if altered oxidative respiration efficiency was responsible for the observed antibiotic sensitivity patterns in the $\Delta p d t a S$ strain, we utilized the Alamar blue assay and 2,3,5-thriphenyl tetrazolium chloride reduction assay (TTC assay), commonly used redox indicators of cellular respiration. $M$. smegmatis $\Delta p d t a S$ cells did not show any significant changes in the ability to utilize resazurin as the electron acceptor in the electron transport chain compared to wild-type cells (Figure 2A). As the reduction of Alamar blue can be connected to various reductive forces in the cell, we have utilized a similar, more targeted method with TTC as the 
TABLE 1 | Minimum inhibitory concentration (MIC) of antibiotics used in that studies.

\begin{tabular}{lccc}
\hline & \multicolumn{3}{c}{ MIC $(\boldsymbol{\mu} \mathbf{g} / \mathbf{m l})$} \\
\cline { 2 - 4 } & Ms-wt & $\boldsymbol{\Delta}$ pdtas & $\boldsymbol{\Delta} \mathbf{p d t a S}-\mathbf{p d t a S}$ \\
\hline Kanamycin & 1.5 & 0.75 & 1.5 \\
Streptomycin & 0.625 & 0.312 & 0.625 \\
Dihydrostreptomycin & 0.312 & 0.156 & 0.312 \\
Apramycin & 1.25 & 1.25 & 1.25 \\
Sisomicin & 2 & 2 & 2 \\
Tetracycline & 0.25 & 0.5 & 0.25 \\
\hline
\end{tabular}

electron acceptor. The reduction of colorless TCC to red TPF (1,3,5-tri phenylformazan) in M. smegmatis cells was visible after $2 \mathrm{~h}$ of incubation at $37^{\circ} \mathrm{C}$. The measurement of absorbance at $480 \mathrm{~nm}$ consistently showed decreased utilization of TTC by approximately $9 \%$ and $17 \%$ of $\Delta p d t a S$ cells after 2 or $6 \mathrm{~h}$ of incubation, respectively, when compared to TTC reduction efficiency measured in wild-type cells (Figure 2B).

Among the mechanisms that could contribute to the sensitization of $\Delta p d t a S$ to aminoglycosides, one should consider the efficiency of uptake of these antibiotics and the intracellular inactivation of these drugs via enzymatic conversion into inactive derivatives or via drug efflux mechanisms (Garneau-Tsodikova and Labby, 2016). Likewise, the uptake of aminoglycosides depends on the efficiency of an electron flow through the respiratory chain, which could be modestly affected in $\Delta p d t a S$ as indicated by a tetrazolium reduction assay. To assess the above possibilities, we have determined the concentrations of intracellularly deposited streptomycin by the wild-type and $\Delta p d t a S \quad M$. smegmatis cells pre-incubated with this anti-tuberculosis drug. The intracellular levels of the tested aminoglycoside were monitored using the competitive ELISA immunoassay. Exponentially grown bacteria were exposed to $\mathrm{SM}$ at a concentration of $0.7 \mu \mathrm{g} / \mathrm{ml}$ for 60 and $180 \mathrm{~min}$. The control bacilli were incubated for the same amount of time without the antibiotic. The resultant cell lysates were used to measure the concentration of SM released from the disrupted cells. The concentration of SM in lysates obtained from wild-type and $\Delta p d t a S$ M. smegmatis exposed to the antibiotic for $60 \mathrm{~min}$ enriched $45.35( \pm 15.83)$ and $54.22( \pm 5.18) \mathrm{ng} / \mathrm{ml}$, respectively. However, the intracellular concentrations of SM in the lysates obtained from cells exposed to this drug for additional $2 \mathrm{~h}$ (180 min) were significantly higher and were calculated as 103.89
A

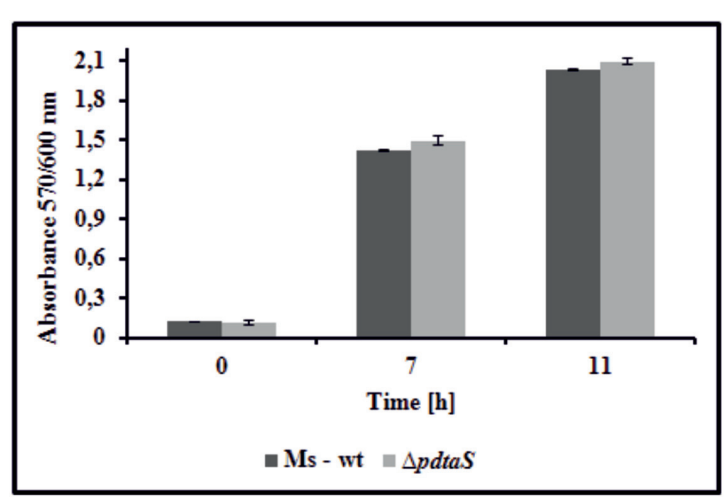

B

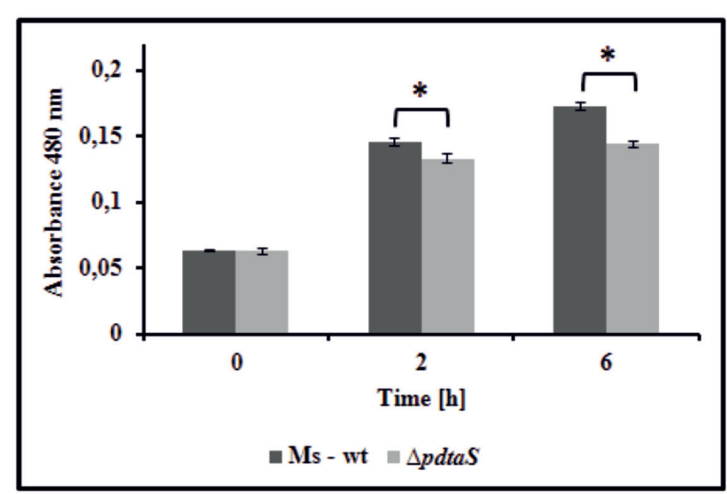

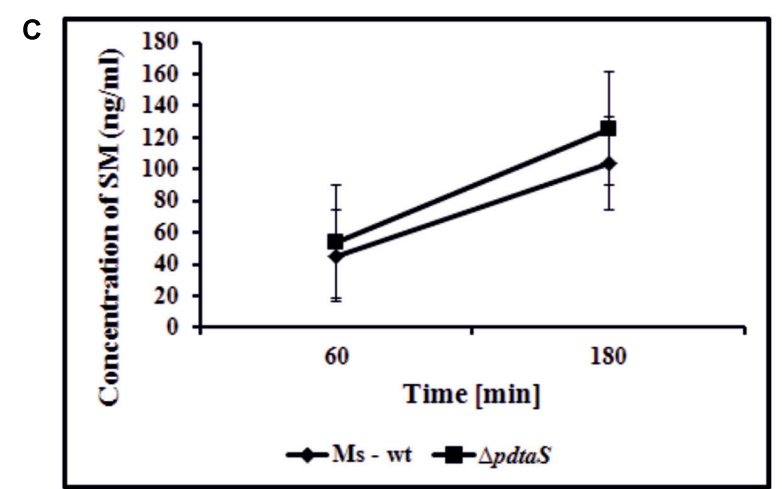

FIGURE 2 | Insufficiency of PdtaS affects the oxidative respiration efficiency. (A) Time dependent Alamar blue metabolic activity of the reduced form of resazurin by wild-type and $\triangle$ pdtaS M. smegmatis cells. Absorbance at 570/600 nm values are means \pm standard errors from three independent experiments. (B) The in vivo reduction of redox indicator $-\Pi T C$ in wild-type and $\Delta p d t a S M$. smegmatis strains. Absorbance at $480 \mathrm{~nm}$ values are means \pm standard error from three independent experiments. All means marked with * $(p<0.001)$ are significantly different from the control in Student's $t$-test analysis. (C) The uptake of streptomycin by wild-type and $\Delta$ pdtaS cells monitored by competitive ELISA immunoassay. The bacterial cells were exposed to SM (0.7 $\mu \mathrm{g} / \mathrm{ml})$ for 60 and 180 min and concentration of intracellularly deposited antibiotic was measured. The mean \pm standard deviation values from three independent experiments are shown. 
$( \pm 19.94)$ and $125.45( \pm 11.45) \mathrm{ng} / \mathrm{ml}$ for wild-type and mutant lysates, respectively (Figure 2C). The concentration of SM in the control mycobacterial cells (growing without an antibiotic) fell below $1 \mathrm{ng} / \mathrm{ml}$ at both experimental time points of 60 and $180 \mathrm{~min}$. Based on the above data, we concluded that the uptake of SM was not significantly affected in the $\Delta p d t a S$ mutant cells, and the sensitization of the mutant to aminoglycosides was not due to an increased concentration of intracellularly deposited antibiotics.

\section{The rRNA Expression Levels Are Not Affected in the $\Delta p d t a S$ Mutant}

Under optimal growth conditions, i.e., rich laboratory culturing media, rRNA transcription in bacteria proceeds as a single polycistronic transcript without interruptions, resulting in proper secondary structure folding and maturation of the transcribed rRNA into three equally abundant species: 16S, $23 \mathrm{~S}$ and 5S. The pre-rRNA transcript contains relatively long $5^{\prime}$ UTR and the regions encoding mature fragments are separated by intratranscribed spacer regions (ITS). The $5^{\prime}$ UTR and the ITS1 between $16 \mathrm{~S}$ and $23 \mathrm{~S}$ contain defined antitermination boxes, which require binding of antitermination factors in order to prevent RNA polymerase pausing or premature disengagement during $r r n$ operon transcription (Figure 3A). In other microorganisms, as well as mycobacteria, these boxes are known to bind proteins of the Nus antitermination complex, as well as yet unknown additional antitermination factors (Arnvig et al., 2004; Beuth et al., 2005).

The non-coding regions not only serve as mechanism for antitermination driven regulation of $r r n$ expression but also influence the maturation pathway that will lead to production of the final rRNA species. They are partially self-complementary, allowing processing of the resulting double stranded RNA by RNase III to initiate appropriate maturation of rRNA. Thus, lack of antitermination may not only produce shorter pre-rRNA species but may also lead to aberrant or alternative maturation. On the other hand, changes in the rRNA itself could translate into altered sensitivity or resistance to aminoglycosides. Since PdtaR, a cellular partner of PdtaS, is believed to be involved in antitermination, we have decided to assess isolated RNA profiles of $M$. smegmatis and the $\Delta p d t a S$ mutant. Carrying out Northern blotting with radiolabeled oligonucleotide probes able to hybridize specifically to mature $16 \mathrm{~S}$ or $5 \mathrm{~S}$ species or $16 \mathrm{~S}$ and $23 \mathrm{~S}$ precursors (complementary to corresponding ITS regions), we controlled for the appropriate rRNA species and their precursors. Under the conditions tested, we failed to observe significantly altered ratios of these non-coding RNA species between the tested strains. We could observe somewhat decreased levels of the mature $5 \mathrm{~S}$ for the mutant RNA profiles on the Northern blots with $5 \mathrm{~S}$ binding probes (Figure 3A). To cross-validate the above results, we evaluated 16S, 23S and $5 \mathrm{~S}$ transcription in $\Delta p d t a S$ and $M$. smegmatis wild-type cells by qRT-PCR relative to specific gene copy numbers. Total RNA was extracted from cells at logarithmic and stationary phases of growth following a previously published protocol (Pawelczyk et al., 2011). The collected data revealed no significant changes in 16S, 23S, and 5S transcript levels for M. smegmatis cells obtained from both logarithmic and stationary phases of growth (Figure 3B). Thus, we do not consider these results as indicative of dramatic problems with the antitermination of the rrn operons in M. smegmatis lacking PdtaS.

\section{Altered Ratio of Ribosomal Subunits and Differences in 305 Protein Content May $B e$ the Main Causes of Unusual Antibiotic Resistance Patterns of the $\Delta$ pdtaS Mutant}

Previous studies on $\mathrm{rrn}$ antitermination in E. coli suggested that the polar expression of precursor rRNA species has a more apparent impact on the ribosomal subunits ratio in the bacterial cell than it has on rRNA levels (Quan et al., 2005). To check whether removal of PdtaS causes any changes to the quantity and quality of the ribosomal subunits, we isolated ribosomes from $M$. smegmatis and the respective $\Delta p d t a S$ strain and resolved them on linear gradients of sucrose using centrifugal force.

Under typical circumstances, the $30 \mathrm{~S}$ small subunit of the ribosome is present within the cell at roughly the same amounts as the large subunit, the 50S. Together they form the 70S subunit while actively translating a transcript, and if there are multiple ribosomes placed on an intact transcript they may be observed as polysomes on sucrose gradients. The mycobacterial small subunit is typically composed of approximately 20 proteins and $16 \mathrm{~S}$ rRNA, whereas the large subunit is formed of approximately 29 proteins, the large rRNA fragment $-23 \mathrm{~S}$ and small 5S (Shasmal and Sengupta, 2012). The 50S subunit, even though present at an equivalent molecular ratio, is thus emitting more signal when monitored by UV 260 or $280 \mathrm{~nm}$ for nucleic acid and protein signal detection, respectively. While this was indeed the case for our wild-type M. smegmatis preparations (Figure 4A, left side panel), the ribosome profiles from the $\Delta p d t a S$ mutant very consistently showed elevated signal for the $30 \mathrm{~S}$ subunit (Figure 4A, right side panel). The overall signal height repeatedly exceeded the signal coming from $50 \mathrm{~S}$ when gradients were monitored at UV $260 \mathrm{~nm}$, indicating the complex mass of $30 \mathrm{~S}$ subunits may be higher in those cells than the mass from 50S. The difference in signal strength was also very apparent when looking at UV $280 \mathrm{~nm}$ for protein signal (data not shown).

Ribosomal subunits isolated during fractionation of mycobacterial lysates on sucrose gradients were further subjected to comparative proteomic analysis. Isolated fractions corresponding to individual ribosomal subunits were resolved on SDS-PAGE gels, and a single visually appealing difference was spotted between ribosomal profiles of the wild-type and mutant strains. A single protein band found to be overrepresented in the 30 S subunits of the $\Delta p d t a S$ was excised from the SDS-PAGE gel (Figure 4B) and identified by mass spectrometry analysis as translation elongation factor TUF (Supplementary Table S3). In parallel, the fractions containing ribosomal subunits were also subjected to total proteomic analysis by mass spectrometry. The identification of individual proteins in each sample were conducted using label free quantification with help of MaxQuant software. We confirmed that individual fractions contained 

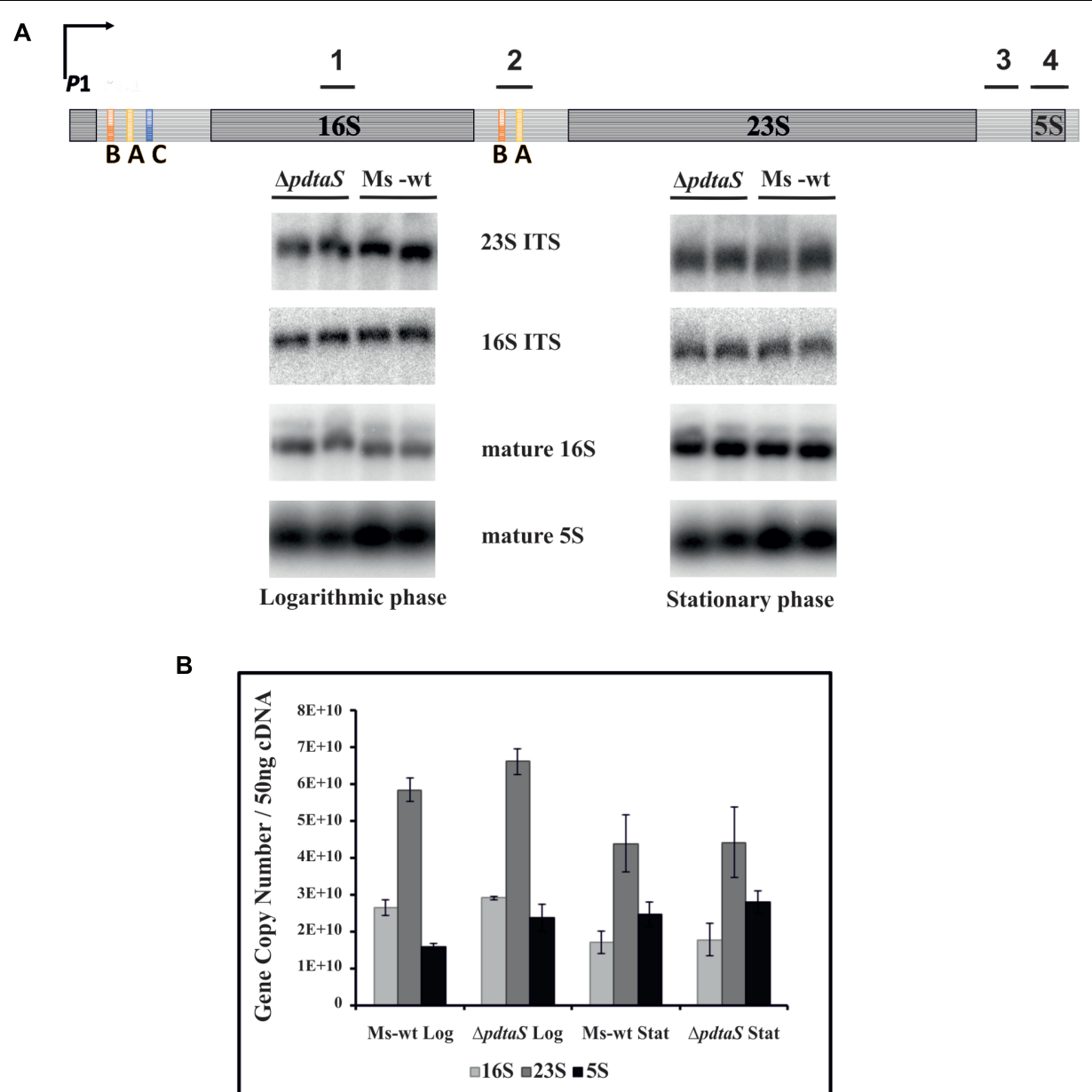

FIGURE 3 | The expression levels of the $r$ in is not significantly affected by deficiency of PdtaS. (A) Schematic of antitermination within the M. smegmatis rrn operons is shown with marked Northern hybridization sites: 1-16S mature; 2-16S ITS; 3-23S ITS; 4-5S mature. $2 \mu \mathrm{g}$ of total RNA from wild-type or $\Delta$ pdtaS cells from logarithmic and stationary phases of growth were resolved on a $2 \%$ agarose gel under denaturing conditions. Mature $16 \mathrm{~S}$ and $5 \mathrm{~S}$, as well as precursor p16S and p23S, were monitored by Northern blotting analysis with probes complementary to mature or ITS regions, respectively. (B) qRT-PCR analysis of 16S, 23S and 5S transcript levels in M. smegmatis $\Delta$ pdtaS and wild-type cells. Total RNA was isolated from cells collected during logarithmic and stationary phases of growth, reverse transcribed and subjected to qRT-PCR using SYBR green chemistry. Relative amounts of gene expression were calculated by standard curve method. The values are presented as copy numbers per 50 ng cDNA used. Log refers to cells at logarithmic phase of growth, whereas Stat refers to cells at stationary phase. RNA samples for this study were isolated from three independently grown cultures. Mean values and standard deviations from three independent experiments are shown.

appropriate subunits and comparative analysis revealed that indeed TUF is overrepresented about five-fold in the spectra of $30 \mathrm{~S}$ subunits of the $\Delta p d t a S$ mutant. In addition to TUF, we have identified three other proteins in the $30 \mathrm{~S}$ subunit of the mutant that differed from the wild-type strain by at least two-fold. Among them, another translation elongation factor TSF and ribosome recycling factor FRR were more abundant in the $30 \mathrm{~S}$ subunits of the mutant and initiation factor IF-3 was over 3 -fold depleted from the mutant's proteomic spectra (Figure $4 \mathrm{C}$ and Supplementary Table S3).

The observed changes in ribosome composition could potentially lead to an altered rate of translation in the investigated strains. To at least partially address this question, we thus decided to test the translation efficiency in an in vivo test. We transformed the wild-type and $\Delta p d t a S$ strains with a plasmid encoding the gene for $\beta$-galactosidase enzyme, which activity can be easily monitored and quantified using a colorimetric assay. Similar strategy is applied to quantify the strength of protein-protein interactions in a bacterial two hybrid system (Karimova et al., 2000). Using similar methodology we were able to determine the amount of $\beta$-galactosidase that was expressed in the investigated strains, normalizing the results to the optical density of each bacterial culture. We have noticed a highly reproducible and statistically significant decrease in the production of $\beta$-galactosidase per $\mathrm{OD}_{600}$ unit of cells, in the mutant strain $(15.9 \pm 0.64)$, comparing to the wild-type $(19.15 \pm 1.37)$, in the absence of antibiotics (Figure 4D). The decrease in the production of $\beta$-galactosidase was apparent in both, the wild-type and control strains, when bacteria were grown in the media containing aminoglycosides: streptomycin 0.7 (Figure 4D), 0.2 and $0.1 \mu \mathrm{g} / \mathrm{ml}$ (data not shown) and dihydrostreptomycin 0.5 (Figure 4D), 0.05 and $0.01 \mu \mathrm{g} / \mathrm{ml}$ (data 
A

Ms - wt A260nm

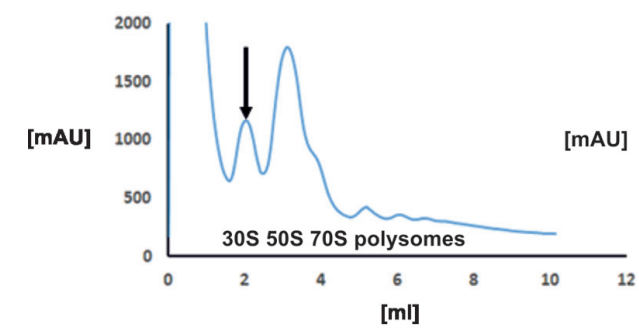

B
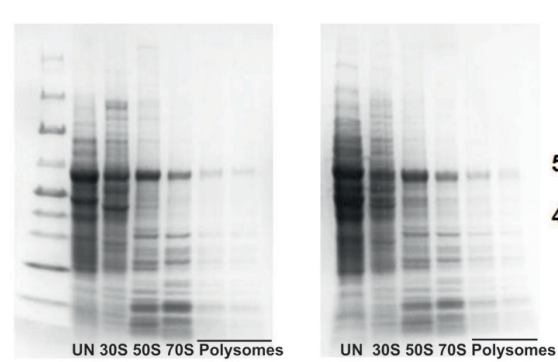

C

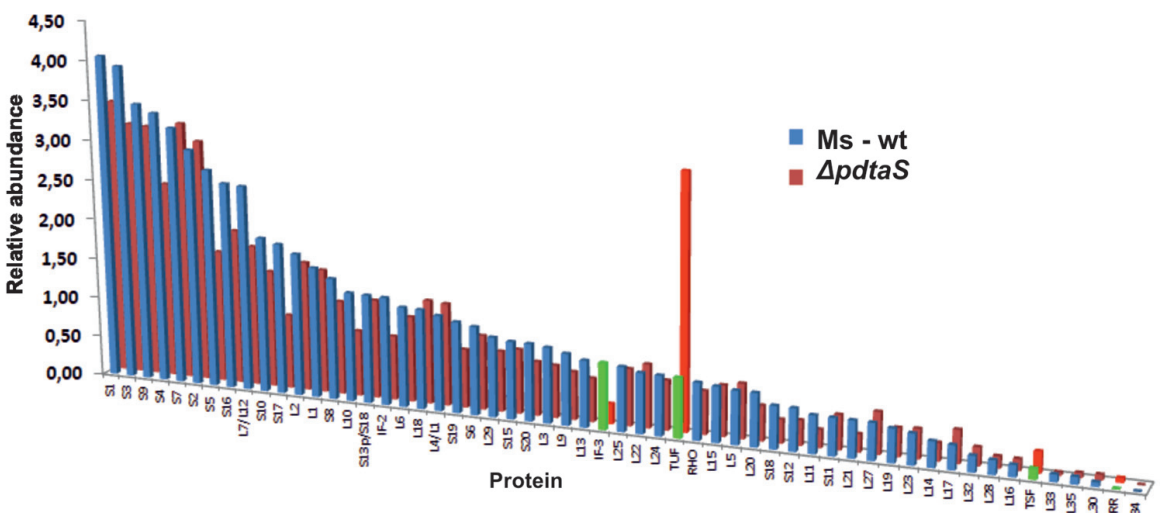

D

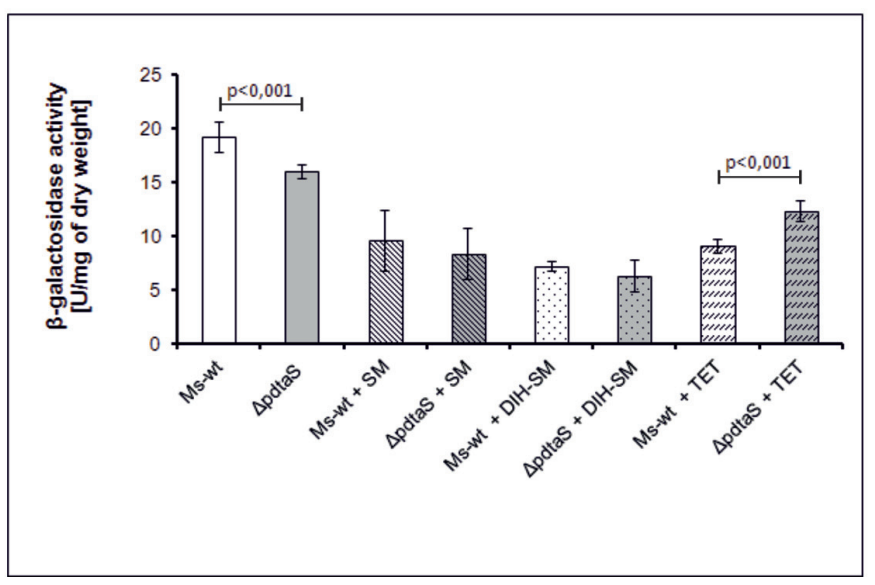

FIGURE 4 | PdtaS deficiency affects 30S:50S ratio and composition of ribosomal subunits in mycobacteria. (A) Resulting accumulation of 30 S ribosome in the strain lacking PdtaS was assessed by examining intracellular ratios of $30 S$ to $50 S$ ribosomal subunits in lysates from exponentially grown $M$. smegmatis strains resolved by ultracentrifugation of cellular lysates on linear gradients of sucrose. Signal monitored at $260 \mathrm{~nm}$ was recorded. Arrows indicate the differences in the levels of $30 \mathrm{~S}$ subunit between the wild-type and mutant strains. (B) SDS-PAGE gel representing fractions containing ribosomal subunits from $\Delta p d t a S$ and wild-type cell extract. (C) Mass spectrometry identification of protein fractionations from the sucrose gradient ribosome fractionation of $\Delta p d t a S$ and wild-type cells. (D) $\beta$-galactosidase activity assay for measurement of translation rates in the wild-type and the $\Delta$ pdtaS strains. The results shown are average from three independent experiments. 
not shown). On the other hand, the addition of tetracycline significantly inhibited the $\beta$-galactosidase production in the wildtype but not in the $\Delta p d t a S$ strain. The mutant strain produced more enzyme $(12.34 \pm 0.96)$ than the wild-type (9.02 \pm 0.67$)$, when grown in the presence of tetracycline, while the growth rate was comparable. The above data was collected after relatively short treatment with antibiotics, at times and concentrations that did not cause substantial amount of bacterial killing in a broth dilution assay, even after $9 \mathrm{~h}$ incubation, assessed by CFU (Figure 1 and data not shown).

\section{DISCUSSION}

To investigate the possible pathways that the PdtaS/R system could potentially control in the mycobacterial cell, we have generated a directed and unmarked mutant strain lacking PdtaS in the saprophytic cousin of $M$. tuberculosis, M. smegmatis. The M. tuberculosis PdtaS (Rv3220c) is known to be a nonessential gene and had previously been disrupted by Parish and collaborators, where the knockout strain of H37Rv with a disrupted pdtaS gene was used for animal infection studies and did not affect the time to death for the SCID mouse model of tuberculosis (Parish et al., 2003).

To gain insight into the growth conditions at which PdtaS could operate, we have looked into a large number of transcriptional profiles for $M$. tuberculosis grown under various conditions and in the presence of various potentially mycobactericidal agents (Reddy et al., 2009; Galagan et al., 2010). PdtaS transcription drops down during macrophage infection (Fontan et al., 2008) and is significantly depleted during hypoxia and in $\mathrm{NAD}^{+}$production knockout strain lacking the nadABC operon (Rustad et al., 2008; Vilchèze et al., 2010). On the other hand, pdtaS transcript increases over 6 -fold within the first 4 h of reaeration (Sherrid et al., 2010).

We have exploited the BIOLOG Phenotype Microarray screening technology to initiate the search for phenotypes associated with removal of PdtaS histidine kinase from the mycobacterial cell. The screening platform, in a convenient 96 well plate format, is compatible with saprophytic $M$. smegmatis strains, which have a much faster generation time than pathogenic $M$. tuberculosis. This was advantageous as the functions of most TCSSs are highly conserved among various species of bacteria and can usually be cross-validated between species. A similar approach had been previously used to characterize a multidrug efflux pump componentMSMEG_2631 (mmp), the removal of which resulted in an increased susceptibility to phleomycin, bleomycin, capreomycin, amikacin, kanamycin, cetylpyridinium chloride, and several sulfa drugs (Khatri et al., 2013). In the case of our M. smegmatis $\Delta p d t a S$ strain, we were unable to detect strong links between the absence of the histidine kinase and basic metabolism. The PdtaS mutant was, however, more sensitive to the wide range of aminoglycosides as well as transport and respiration inhibitors. On the other hand, the $\Delta p d t a S$ appeared to be more resistant to tetracycline antibiotics such as tetracycline and penimepicycline. The sensitivity of the pdtaS defective strain to aminoglycosides and tetracycline was also verified by classical microbiological methods, such as determination of survival by monitoring the CFU for the wild-type and mutant strains after exposure to drugs. Kanamycin, apramycin, sisomicin, streptomycin and dihydrostreptomycin were all found to be more effective and tetracycline less effective against the $\Delta p d t a S$ mutant then the wild-type. Importantly, complementation of the mutant with a plasmid encoding an intact copy of pdtaS reversed the observed phenotypes back to wild-type levels. Moreover, using the MABA assay, the MIC value for $\Delta p d t a S$ strain was significantly lower in the presence of kanamycin, streptomycin and dihydrostreptomycin and higher in the presence of tetracycline, comparing to control strain. In the case of apramycin and sisomicin we did not observe the difference in MIC value between studied strains. This may be due to the small difference in susceptibility of this strains to the antibiotics used.

The best hits for antibiotics affecting the growth of the $\Delta p d t a S$ strain were aminoglycoside and tetracycline antibiotics known to interfere with the $30 \mathrm{~S}$ subunit of the ribosome (Wilson, 2014). In all but the case of dihydrostreptomycin, the results obtained from the BIOLOG screening platform were consistent with the classical bacteriological assessments of bacterial viability. The presence of dihydrostreptomycin on BIOLOG plates was found to favor metabolic activity of the mutant strain over the wild-type $M$. smegmatis, whereas this $30 \mathrm{~S}$ targeting antibiotic inhibited the growth of the mutant more efficiently than the wild-type when incubated in the growth media before plating CFU. The kinetic plot analysis of control plates (M. smegmatis wild-type) PM19 for G06-8 carrying different concentrations of dihydrostreptomycin showed significant differentiations in particular repeats, which might explain the discrepancies between microarray and classical growth analysis in the case of this antibiotic.

In general, the strain lacking PdtaS was more sensitive to aminoglycosides and more resistant to tetracyclines, drugs affecting $30 \mathrm{~S}$ subunit of ribosomes. Thus, further investigation of the underlying mechanism of sensitization of the $\Delta p d t a S$ strain to $30 \mathrm{~S}$ targeting drugs was continued. There are several mechanisms that contribute to the bacterial resistance/sensitivity profiles against aminoglycosides and tetracyclines. Among them are mutations or modifications of rRNA, qualitative and quantitative rearrangements of the ribosomal composition, drug uptake or efflux mechanisms and finally enzymatic inactivation of antibiotics. We attempted to systematically test the most likely hypothesis behind the observed bactericidal effects. We initially explored the potential of rRNA molecules to confer sensitivity against chosen antibiotics. This notion was particularly attractive as it has been proposed that the ribosomal RNA must be undergoing extensive antitermination in order to prevent polar expression of its species and to allow the appropriate RNA structure folding needed for its proper maturation (Gourse et al., 1996; Kaczanowska and Ryden-Aulin, 2007). Studies from E. coli showed that most of the rrn operons have present antitermination boxA, boxB, and boxC sequences downstream to the P2 transcription start site (promoter 2) and a second set of antitermination boxes within the ITS 
between the $16 \mathrm{~S}$ and $23 \mathrm{~S}$ rRNA sequences, which both are processed via NusA mediated antitermination (Kaczanowska and Ryden-Aulin, 2007). Antitermination within the rrn operons is ubiquitous among multiple bacterial species and boxA, B and $\mathrm{C}$ sequences of $M$. tuberculosis had been determined to be present within the leader and ITS sequences of the $r r n$ molecule in this pathogen (Berg et al., 1989; Beuth et al., 2005). In E. coli, as well as in mycobacteria, the $r r n$ operons are under the control of the two promoters P1 and P2 or P1 and pCL1, respectively. Most bacterial species encode for multiple rrn operons on their genomes, however, $M$. tuberculosis encodes for only a single rrn operon. $M$. smegmatis, on the other hand, encodes for two rrn operons and can drive expression of each of them from at least 3 distinct promoters (Gonzalez-y-Merchand et al., 1996). We applied Northern blotting and qRT-PCR to detect the levels of expression of precursors and mature species of rRNA in the wild-type and $\Delta$ pdtaS M. smegmatis. While we could observe a slight difference in the amount of mature $5 \mathrm{~S}$ between the strains using the Northern blot analysis, we were unable to confirm that polar expression of the rrn operon was responsible for this observation judging from qRT-PCR results. We even carried out $\mathrm{qRT}$-PCR reactions with cDNAs generated using random hexamers (data not shown) in parallel with transcript specific primers and still detected no hints of the polar expression of the rRNA species. We concluded that rrn antitermination may not be PdtaS dependent and other mechanisms may be responsible for the observed aminoglycoside sensitization phenotype.

The next logical step was to look at the ribosomes themselves. We investigated the ratio of ribosomal subunits $30 \mathrm{~S} / 50 \mathrm{~S}$ in the wild-type and mutant strain, detecting a relative overproduction of the ribosomal $30 S$ subunit in $\Delta p d t a S$. The ribosomal subunits were also separated and analyzed by mass spectrometry, revealing that the composition of ribosomal subunits in the mutant strain is significantly affected. Among the most altered ribosome building blocks were the two translation elongation factors TUF and TSF and the ribosome recycling factor RRF, which were all more abundant on the mutant's $30 \mathrm{~S}$ subunit. Persistence of elongation factors and ribosome recycling factors on the $30 \mathrm{~S}$ may suggest that ribosome recycling may be more common in the $\Delta p d t a S$ than in the wild-type. However, IF-3 was found to be underrepresented on the mutant's $30 \mathrm{~S}$ compared to the wild-type strain, and this protein is known to stabilize the transiently recycled $30 \mathrm{~S}$ subunits by preventing reassociation into $70 S$ in E. coli (Hirokawa et al., 2005). Studies in $M$. tuberculosis showed that kanamycin and streptomycin both affect the positioning of the IF-3 on the $30 \mathrm{~S}$ platform and the overall dynamics of $30 \mathrm{~S}$ association with the IF-3, thus perturbing the translation initiation (Chulluncuy et al., 2016). Low abundance of IF-3 on the mutant's ribosomes may indicate that these $30 \mathrm{~S}$ ribosomal subunits remain in conformation, thus favoring the inhibition of translation by aminoglycosides. Aminoglycosides could possibly further decrease the affinity of IF-3 to the 30 S platform and block the translation initiation. Persistence of translation elongation factors TUF and TSF on the ribosomes may suggest that the rate of translation in the $\Delta p d t a S$ strain is affected as both proteins interact and are needed for efficient guanine nucleotide exchange during peptide chain elongation (Jonak et al., 1998). Indeed, the efficiency of translation measured by $\beta$-galactosidase activity was down-regulated in the $\Delta p d t a S$ strain comparing to the wild-type strain. The addition of aminoglycosides additionally decreased the efficiency of translation in both the wild-type and mutant strain, however, without statistically significant differences between strains. On the other hand, the tetracycline inhibited the $\beta$-galactosidase activity normalized to the optical density of cultures more efficiently in a wild-type strain than in the $\Delta p d t a S$ mutant. Our results indicate that the translation efficiency in the mutant strain is down regulated due to the lack of PdtaS protein, however, the translation process in the mutant strain is less sensitive to the presence of tetracycline, likely because of its lower affinity to the ribosome modified in $\Delta p d t a S$ strain. We hypothesize that the binding of tetracyclines and/or aminoglycosides to the modified ribosomes is altered in the $\Delta p d t a S$ mutant, however we are not able to exclude the possibility that the modified protein composition of the mutant's ribosomes may partially affect their function, making the bacilli more sensitive to some antibiotics targeting $30 \mathrm{~S}$ subunits.

We have observed resistance of the mutant against tetracycline, penimepicycline and blastocidin S, all binding to or influencing $30 \mathrm{~S}$ subunit. Ribosomal protection is one of the mechanisms available to confer resistance against tetracyclines, and ribosome protection proteins are homologs of elongation factor TUF, or EF-G, displaying GTPase activity to drive conformational changes of the ribosome and thus make it unavailable for tetracycline binding (Connell et al., 2003). We speculate that persistence of elongation factors TUF and TSF on ribosomes of $\Delta p d t a S$ could also provide some level of ribosome protection against tetracyclines, keeping the ribosomes in a confirmation that provides resistance to tetracyclines but makes them more available for binding of aminoglycosides.

On the BIOLOG screening platform, $\Delta p d t a S$ was sensitized not only to aminoglycosides but also inhibitors of respiration and electron transport. This would be consistent with the transcriptomic profiles available for PdtaS expression from M. tuberculosis mentioned earlier and would suggest the link between the expression of this protein and availability of oxygen. On the other hand, the uptake of aminoglycosides into bacterial cells requires proton motive force (PMF) that is generated by electron flow through the respiratory chain (Damper and Epstein, 1981). PMF is largely generated by the respiratory complex I, $\mathrm{NADH}$ (reduced form of nicotinamide adenine dinucleotide) dehydrogenase (Nuo) and, to some extent, by complex II, succinate dehydrogenase (Sdh) (Simon et al., 2008). It was recently shown that the $\mathrm{Fe}-\mathrm{S}$ cluster biogenesis machineries play a key role in aminoglycoside resistance by affecting their PMFenergized uptake. As a consequence, aminoglycosides, whose uptake is strongly PMF-dependent, cannot reach the ribosome, their cytoplasmic target (Ezraty et al., 2013). On the other hand, the removal of PdtaS could cause secondary effects, like increased aminoglycoside uptake as the result of affecting an electron flow through the respiratory chain. Activity of aminoglycoside 
specific efflux pumps or enzymatic inactivation of the drugs could also affect the antibiotic resistance profile. We hypothesized whether PdtaS could influence the cellular levels of PMF and thus interfere with the transport of aminoglycosides through the cell membrane. Oxidative respiration efficiency was determined by Alamar blue and TTC assays, and the streptomycin uptake was monitored to identify the role of aminoglycoside transport in the observed phenotype. We did not observe any significant changes in reduction of resazurin by $M$. smegmatis mutant and wild-type cells in the Alamar blue assay. The TTC assay revealed a rather modest but statistically significant decrease in the rate of reduction of tetrazolium in $\Delta p d t a S$ compared to the wild-type strain. Metabolic activity of $\Delta p d t a S$ was also reduced in the presence of iodonitro tetrazolium violet salts on the BIOLOG screen, further confirming that PdtaS activity has an influence on the respiratory chain efficiency. Logically, this should translate into a decreased PMF and decreased uptake of aminoglycosides. However, monitoring the uptake of streptomycin using a competitive ELISA immunoassay did not show significant differences in the levels of intracellularly deposited streptomycin between the mutant and wild-type strains.

Together, we conclude that ribosomal composition and/or the conformational changes associated with it, rather than other effects, are the key features responsible for the change of antibiotic resistance patterns of the $\Delta p d t a S$, as the group of compounds targeting ribosome assembly was diverse and oriented toward various steps of the translation process. We believe that the mechanism presented here may be a contributing factor to mycobacterial antibiotic susceptibility during treatment. This is particularly important as streptomycin is currently still considered a first-line drug, and kanamycin and amikacin are the second line of defense used to treat tuberculosis in patients. A potential treatment strategy can be designed using models

\section{REFERENCES}

Arnvig, K. B., Pennell, S., Gopal, B., and Colston, M. J. (2004). A high-affinity interaction between NusA and the rrn nut site in Mycobacterium tuberculosis. Proc. Natl. Acad. Sci. U.S.A. 101, 8325-8330. doi: 10.1073/pnas.0401287101

Banfi, E., Scialino, G., and Monti-Bragadin, C. (2003). Development of a microdilution method to evaluate Mycobacterium tuberculosis drug susceptibility. J. Antimicrob. Chemother. 52, 796-800. doi: 10.1093/jac/dkg439

Berg, K. L., Squires, C., and Squires, C. L. (1989). Ribosomal RNA operon antitermination. Function of leader and spacer region box B-box A sequences and their conservation in diverse micro-organisms. J. Mol. Biol. 209, 345-358. doi: 10.1016/0022-2836(89)90002-8

Beuth, B., Pennell, S., Arnvig, K. B., Martin, S. R., and Taylor, I. A. (2005). Structure of a Mycobacterium tuberculosis NusA-RNA complex. EMBO J. 24, 3576-3587. doi: 10.1038/sj.emboj.7600829

Boudes, M., Lazar, N., Graille, M., Durand, D., Gaidenko, T. A., Stewart, V., et al. (2012). The structure of the NasR transcription antiterminator reveals a one-component system with a NIT nitrate receptor coupled to an ANTAR RNA-binding effector. Mol. Microbiol. 85, 431-444. doi: 10.1111/j.1365-2958. 2012.08111.x

Bretl, D. J., Demetriadou, C., and Zahrt, T. C. (2011). Adaptation to environmental stimuli within the host: two-component signal transduction systems of Mycobacterium tuberculosis. Microbiol. Mol. Biol. Rev. 75, 566-582. doi: 10. 1128/MMBR.05004-11 like the PdtaS knockout system to take advantage of their drug susceptibility and avoid natural drug resistance mechanisms.

\section{AUTHOR CONTRIBUTIONS}

$\mathrm{RP}, \mathrm{JD}$, and AR-G conceived and designed the experiments. KD, $\mathrm{RP}, \mathrm{AR}-\mathrm{G}, \mathrm{AZ}, \mathrm{BD}, \mathrm{AZ}$, and PP performed the experiments. KD, RP, AR-G, AŻ, BD, AZ, PP, and JD analyzed the data. KD, RP, PP, and JD wrote the paper.

\section{FUNDING}

This work was supported by Foundation for Polish Science, PARENT-BRIDGE Program, co-financed by the European Union with European Regional Development; BRIDGE/2013-8/10 (RP).

\section{ACKNOWLEDGMENTS}

The authors thank prof. Andrzej Dziembowski from Institute of Biochemistry and Biophysics, PAS, Warsaw, Poland, for help with ribosome fractionation experiments, Dr. Małgorzata KoryckaMachała for technical assistance and SANGER sequencing of all the constructs used in the study and Dr. Anna Brzostek for sharing the lacZ-pMV306 vector.

\section{SUPPLEMENTARY MATERIAL}

The Supplementary Material for this article can be found online at: https://www.frontiersin.org/articles/10.3389/fmicb. 2017.02145/full\#supplementary-material

Brzostek, A., Pawelczyk, J., Rumijowska-Galewicz, A., Dziadek, B., and Dziadek, J. (2009). Mycobacterium tuberculosis is able to accumulate and utilize cholesterol. J. Bacteriol. 191, 6584-6591. doi: 10.1128/JB.00488-09

Chulluncuy, R., Espiche, C., Nakamoto, J. A., Fabbretti, A., and Milon, P. (2016). Conformational response of 30S-bound IF3 to A-Site Binders Streptomycin and Kanamycin. Antibiotics (Basel) 5:E38. doi: 10.3390/antibiotics 5040038

Chung, G. A. C., Aktar, Z., Jackson, S., and Duncan, K. (1995). High-throughput screen for detecting antimycobacterial agents. Antimicrob. Agents Chemother. 39, 2235-2238. doi: 10.1128/AAC.39.10.2235

Connell, S. R., Tracz, D. M., Nierhaus, K. H., and Taylor, D. E. (2003). Ribosomal protection proteins and their mechanism of tetracycline resistance. Antimicrob. Agents Chemother. 47, 3675-3681. doi: 10.1128/AAC.47.12.3675-3681.2003

Damper, P. D., and Epstein, W. (1981). Role of the membrane potential in bacterial resistance to aminoglycoside antibiotics. Antimicrob. Agents Chemother. 20, 803-808. doi: 10.1128/AAC.20.6.803

Dyer, C. M., Vartanian, A. S., Zhou, H., and Dahlquist, F. W. (2009). A molecular mechanism of bacterial flagellar motor switching. J. Mol. Biol. 388, 71-84. doi: 10.1016/j.jmb.2009.02.004

Dziadek, J., Rajagopalan, M., Parish, T., Kurepina, N., Greendyke, R., Kreiswirth, B. N., et al. (2002). Mutations in the CCGTTCACA DnaA box of Mycobacterium tuberculosis oriC that abolish replication of oriC plasmids are tolerated on the chromosome. J. Bacteriol. 184, 3848-3855. doi: 10.1128/JB.184. 14.3848-3855.2002 
Esposito, A. M., Mateyak, M., He, D., Lewis, M., Sasikumar, A. N., Hutton, J., et al. (2010). Eukaryotic polyribosome profile analysis. J. Vis. Exp. 40:e1948. doi: $10.3791 / 1948$

Ezraty, B., Vergnes, A., Banzhaf, M., Duverger, Y., Huguenot, A., Brochado, A. R., et al. (2013). Fe-S cluster biosynthesis controls uptake of aminoglycosides in a ROS-less death pathway. Science 340, 1583-1587. doi: 10.1126/science.1238328

Fontan, P., Aris, V., Ghanny, S., Soteropoulos, P., and Smith, I. (2008). Global transcriptional profile of Mycobacterium tuberculosis during THP-1 human macrophage infection. Infect. Immun. 76, 717-725. doi: 10.1128/IAI.00974-07

Franzblau, S. G., Witzig, R. S., Mclaughlin, J. C., Torres, P., Madico, G., Hernandez, A., et al. (1998). Rapid, low-technology MIC determination with clinical Mycobacterium tuberculosis isolates by using the microplate Alamar Blue assay. J. Clin. Microbiol. 36, 362-366.

Gagala, I., Izydorczyk, K., Jurczak, T., Pawelczyk, J., Dziadek, J., WojtalFrankiewicz, A., et al. (2014). Role of environmental factors and toxic genotypes in the regulation of microcystins-producing cyanobacterial blooms. Microb. Ecol. 67, 465-479. doi: 10.1007/s00248-013-0303-3

Galagan, J. E., Sisk, P., Stolte, C., Weiner, B., Koehrsen, M., Wymore, F., et al. (2010). TB database 2010: overview and update. Tuberculosis 90, 225-235. doi: 10.1016/j.tube.2010.03.010

Garneau-Tsodikova, S., and Labby, K. J. (2016). Mechanisms of resistance to aminoglycoside antibiotics: overview and perspectives. Medchemcomm 7, 11-27. doi: 10.1039/C5MD00344J

Gonzalez-y-Merchand, J. A., Colston, M. J., and Cox, R. A. (1996). The rRNA operons of Mycobacterium smegmatis and Mycobacterium tuberculosis: comparison of promoter elements and of neighbouring upstream genes. Microbiology 142( Pt 3), 667-674. doi: 10.1099/13500872-142-3-667

Gourse, R. L., Gaal, T., Bartlett, M. S., Appleman, J. A., and Ross, W. (1996). rRNA transcription and growth rate-dependent regulation of ribosome synthesis in Escherichia coli. Annu. Rev. Microbiol. 50, 645-677. doi: 10.1146/annurev. micro.50.1.645

Haydel, S. E., Malhotra, V., Cornelison, G. L., and Clark-Curtiss, J. E. (2012). The prrAB two-component system is essential for Mycobacterium tuberculosis viability and is induced under nitrogen-limiting conditions. J. Bacteriol. 194, 354-361. doi: 10.1128/JB.06258-11

Hirokawa, G., Nijman, R. M., Raj, V. S., Kaji, H., Igarashi, K., and Kaji, A. (2005). The role of ribosome recycling factor in dissociation of $70 \mathrm{~S}$ ribosomes into subunits. RNA 11, 1317-1328. doi: 10.1261/rna.2520405

Jonak, J., Anborgh, P. H., and Parmeggiani, A. (1998). Interaction of EF-Tu with EF-Ts: substitution of His-118 in EF-Tu destabilizes the EF-Tu x EF-Ts complex but does not prevent EF-Ts from stimulating the release of EF-Tu-bound GDP. FEBS Lett. 422, 189-192. doi: 10.1016/S0014-5793(98)00007-6

Kaczanowska, M., and Ryden-Aulin, M. (2007). Ribosome biogenesis and the translation process in Escherichia coli. Microbiol. Mol. Biol. Rev. 71, 477-494. doi: 10.1128/MMBR.00013-07

Karimova, G., Ullmann, A., and Ladant, D. (2000). A bacterial two-hybrid system that exploits a cAMP signaling cascade in Escherichia coli. Methods Enzymol. 328, 59-73. doi: 10.1016/S0076-6879(00)28390-0

Khatri, B., Fielder, M., Jones, G., Newell, W., Abu-Oun, M., and Wheeler, P. R. (2013). High throughput phenotypic analysis of Mycobacterium tuberculosis and Mycobacterium bovis strains' metabolism using biolog phenotype microarrays. PLOS ONE 8:e52673. doi: 10.1371/journal.pone.0052673

King, G. M. (2003). Uptake of carbon monoxide and hydrogen at environmentally relevant concentrations by mycobacteria. Appl. Environ. Microbiol. 69, 7266-7272. doi: 10.1128/AEM.69.12.7266-7272.2003

Leonard, B., Coronel, J., Siedner, M., Grandjean, L., Caviedes, L., Navarro, P., et al. (2008). Inter- and intra-assay reproducibility of microplate Alamar blue assay results for isoniazid, rifampicin, ethambutol, streptomycin, ciprofloxacin, and capreomycin drug susceptibility testing of Mycobacterium tuberculosis. J. Clin. Microbiol. 46, 3526-3529. doi: 10.1128/JCM.02083-07

Luna-Herrera, J., Martinez-Cabrera, G., Parra-Maldonado, R., Enciso-Moreno, J. A., Torres-Lopez, J., Quesada-Pascual, F., et al. (2003). Use of receiver operating characteristic curves to assess the performance of a microdilution assay for determination of drug susceptibility of clinical isolates of Mycobacterium tuberculosis. Eur. J. Clin. Microbiol. Infect. Dis. 22, 21-27.

Morth, J. P., Gosmann, S., Nowak, E., and Tucker, P. A. (2005). A novel twocomponent system found in Mycobacterium tuberculosis. FEBS Lett. 579, 4145-4148. doi: 10.1016/j.febslet.2005.06.043
Parish, T., Smith, D. A., Kendall, S., Casali, N., Bancroft, G. J., and Stoker, N. G. (2003). Deletion of two-component regulatory systems increases the virulence of Mycobacterium tuberculosis. Infect. Immun. 71, 1134-1140. doi: 10.1128/IAI. 71.3.1134-1140.2003

Parish, T., and Stoker, N. G. (2000). Use of a flexible cassette method to generate a double unmarked Mycobacterium tuberculosis tlyA plcABC mutant by gene replacement. Microbiology 146( Pt 8), 1969-1975. doi: 10.1099/00221287-1468-1969

Pawelczyk, J., Brzostek, A., Kremer, L., Dziadek, B., Rumijowska-Galewicz, A., Fiolka, M., et al. (2011). AccD6, a Key carboxyltransferase essential for mycolic acid synthesis in Mycobacterium tuberculosis, is dispensable in a nonpathogenic strain. J. Bacteriol. 193, 6960-6972. doi: 10.1128/JB.05638-11

Plocinska, R., Purushotham, G., Sarva, K., Vadrevu, I. S., Pandeeti, E. V. P., Arora, N., et al. (2012). Septal localization of the Mycobacterium tuberculosis MtrB sensor kinase promotes MtrA regulon expression. J. Biol. Chem. 287, 23887-23899. doi: 10.1074/jbc.M112.346544

Plocinski, P., Laubitz, D., Cysewski, D., Stodus, K., Kowalska, K., and Dziembowski, A. (2014). Identification of protein partners in mycobacteria using a single-step affinity purification method. PLOS ONE 9:e91380. doi: 10. 1371/journal.pone.0091380

Quan, S., Zhang, N., French, S., and Squires, C. L. (2005). Transcriptional polarity in rRNA operons of Escherichia coli nusA and nusB mutant strains. J. Bacteriol. 187, 1632-1638. doi: 10.1128/JB.187.5.1632-1638.2005

Rajagopalan, M., Dziedzic, R., Al Zayer, M., Stankowska, D., Ouimet, M. C., Bastedo, D. P., et al. (2010). Mycobacterium tuberculosis origin of replication and the promoter for immunodominant secreted antigen $85 \mathrm{~B}$ are the targets of MtrA, the essential response regulator. J. Biol. Chem. 285, 15816-15827. doi: 10.1074/jbc.M109.040097

Ramesh, A., Debroy, S., Goodson, J. R., Fox, K. A., Faz, H., Garsin, D. A., et al. (2012). The mechanism for RNA recognition by ANTAR regulators of gene expression. PLOS Genet. 8:e1002666. doi: 10.1371/journal.pgen. 1002666

Reddy, T. B. K., Riley, R., Wymore, F., Montgomery, P., Decaprio, D., Engels, R., et al. (2009). TB database: an integrated platform for tuberculosis research. Nucleic Acids Res. 37, D499-D508. doi: 10.1093/nar/gkn652

Rustad, T. R., Harrell, M. I., Liao, R., and Sherman, D. R. (2008). The enduring hypoxic response of Mycobacterium tuberculosis. PLOS ONE 3:e1502. doi: 10. 1371/journal.pone.0001502

Sambrook, J., and Russell, D. W. (2001). Molecular Cloning : A Laboratory Manual. Cold Spring Harbor, NY: Cold Spring Harbor Laboratory Press.

Shasmal, M., and Sengupta, J. (2012). Structural diversity in bacterial ribosomes: mycobacterial $70 \mathrm{~S}$ ribosome structure reveals novel features. PLOS ONE 7:e31742. doi: 10.1371/journal.pone.0031742

Sherrid, A. M., Rustad, T. R., Cangelosi, G. A., and Sherman, D. R. (2010). Characterization of a Clp protease gene regulator and the reaeration response in Mycobacterium tuberculosis. PLOS ONE 5:e11622. doi: 10.1371/journal.pone. 0011622

Shu, C. J., and Zhulin, I. B. (2002). ANTAR: an RNA-binding domain in transcription antitermination regulatory proteins. Trends Biochem. Sci. 27, 3-5. doi: 10.1016/S0968-0004(01)02036-9

Simon, J., Van Spanning, R. J., and Richardson, D. J. (2008). The organisation of proton motive and non-proton motive redox loops in prokaryotic respiratory systems. Biochim. Biophys. Acta 1777, 1480-1490. doi: 10.1016/j.bbabio.2008. 09.008

Snapper, S. B., Melton, R. E., Mustafa, S., Kieser, T., and Jacobs, W. R. Jr. (1990). Isolation and characterization of efficient plasmid transformation mutants of Mycobacterium smegmatis. Mol. Microbiol. 4, 1911-1919. doi: 10.1111/j.13652958.1990.tb02040.x

Szczesny, R. J., Borowski, L. S., Brzezniak, L. K., Dmochowska, A., Gewartowski, K., Bartnik, E., et al. (2010). Human mitochondrial RNA turnover caught in flagranti: involvement of hSuv3p helicase in RNA surveillance. Nucleic Acids Res. 38, 279-298. doi: 10.1093/nar/gkp903

Taber, H. W., Mueller, J. P., Miller, P. F., and Arrow, A. S. (1987). Bacterial uptake of aminoglycoside antibiotics. Microbiol. Rev. 51, 439-457.

Vilchèze, C., Weinrick, B., Wong, K. W., Chen, B., and Jacobs, W. R. Jr. (2010). NAD+ auxotrophy is bacteriocidal for the tubercle bacilli. Mol. Microbiol. 76, 365-377. doi: 10.1111/j.1365-2958.2010.07099.x 
Wiegand, I., Hilpert, K., and Hancock, R. E. W. (2008). Agar and broth dilution methods to determine the minimal inhibitory concentration (MIC) of antimicrobial substances. Nat. Protoc. 3, 163-175. doi: 10.1038/nprot. 2007.521

Wilson, D. N. (2014). Ribosome-targeting antibiotics and mechanisms of bacterial resistance. Nat. Rev. Microbiol. 12, 35-48. doi: 10.1038/nrmi cro3155

Zhou, P., Long, Q., Zhou, Y., Wang, H., and Xie, J. (2012). Mycobacterium tuberculosis two-component systems and implications in novel vaccines and drugs. Crit. Rev. Eukaryot. Gene Expr. 22, 37-52. doi: 10.1615/ CritRevEukarGeneExpr.v22.i1.30
Conflict of Interest Statement: The authors declare that the research was conducted in the absence of any commercial or financial relationships that could be construed as a potential conflict of interest.

Copyright (@ 2017 Dadura, Płocińska, Rumijowska-Galewicz, Płociński, Żaczek, Dziadek, Zaborowski and Dziadek. This is an open-access article distributed under the terms of the Creative Commons Attribution License (CC BY). The use, distribution or reproduction in other forums is permitted, provided the original author(s) or licensor are credited and that the original publication in this journal is cited, in accordance with accepted academic practice. No use, distribution or reproduction is permitted which does not comply with these terms. 